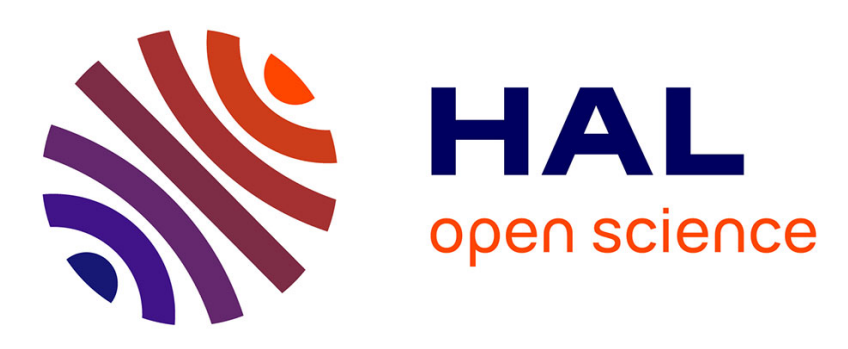

\title{
Analysis of energy exchanges during the interaction between pulsed lightning arcs and metallic plates
}

Rafael Sousa Martins, Philippe Rivière, Clément Zaepffel, Françoise Passilly, Anouar Soufiani

\section{- To cite this version:}

Rafael Sousa Martins, Philippe Rivière, Clément Zaepffel, Françoise Passilly, Anouar Soufiani. Analysis of energy exchanges during the interaction between pulsed lightning arcs and metallic plates. Journal of Applied Physics, 2020, 128 (22), pp.223301. 10.1063/5.0025616 . hal-03074574

\section{HAL Id: hal-03074574 https://hal.science/hal-03074574}

Submitted on 16 Dec 2020

HAL is a multi-disciplinary open access archive for the deposit and dissemination of scientific research documents, whether they are published or not. The documents may come from teaching and research institutions in France or abroad, or from public or private research centers.
L'archive ouverte pluridisciplinaire HAL, est destinée au dépôt et à la diffusion de documents scientifiques de niveau recherche, publiés ou non, émanant des établissements d'enseignement et de recherche français ou étrangers, des laboratoires publics ou privés. 


\title{
Analysis of energy exchanges during the interaction between pulsed lightning arcs and metallic plates
}

\author{
R Sousa Martins ${ }^{1}$, Ph Rivière ${ }^{2}$, C Zaepffel $^{1}$, F Passilly $^{3}$ and A Soufiani ${ }^{2}$ \\ ${ }^{1}$ DPHY, ONERA, Université Paris Saclay, F-91123 Palaiseau - France \\ ${ }^{2}$ Laboratoire EM2C, CNRS UPR288, Université Paris Saclay, CentraleSupélec, \\ 91190 Gif-sur-Yvette - France \\ ${ }^{3}$ DMAS, ONERA, Université Paris Saclay, F-92322 Chatillon - France \\ E-mail: rafael.sousa_martins@onera.fr
}

\begin{abstract}
Lightning electrical arcs lead to high temperature and high pressure air plasmas where radiation is a dominant energy transfer mechanism. The aim of this work is to evaluate the energy exchanges during the arc-electrode interaction for metallic plates impacted by pulsed lightning arcs that can reach $100 \mathrm{kA}$, with peak time of around $13 \mu \mathrm{s}$ and full width at half maximum (FWHM) of $40 \mu \mathrm{s}$. Rear surface temperatures are measured with infrared camera, and an experimental parametric study on current amplitude, material, plate thickness and arc polarity is performed, with a total of eighteen studied configurations. An inverse method using the heat conduction equation and taking into account Joule heating is applied to estimate the incoming heat flux at the plate surface. To compare with experimental results and to analyze the contribution of radiative transfer, calculations of the incoming radiative flux from the arc column on the plate are performed. Experimental time- and space-resolved temperature and pressure distributions of the arc column are used for these computations, which are performed using a line by line calculation based on accurate plasma spectroscopic data, in association with a ray tracing method. An energy budget analysis is proposed and the influence of the different mechanisms is discussed. A transferred energy higher than $300 \mathrm{~J}$ is observed for the $100 \mathrm{kA}$ current waveform. The comparisons show that radiative flux from the arc channel can play an important role in the energy balance at the plate surface.
\end{abstract}

\section{Introduction}

Lightning strike is an important phenomenon in the aeronautical industry, since statistically an aircraft is impacted by one lightning strike every 1000 to 10000 flight hours. ${ }^{1,2}$ During the lightning-aircraft interaction, significant thermo-mechanical constraints are imposed to the aircraft structure at the attachment point, as well as the high current circulation can cause an electromagnetic coupling with internal cables and components. For the new airliner generations, which employ carbon fiber reinforced polymer composite (CFRP) in around 50\% of the aircraft weight, the concerns are even more important. CFRP are more vulnerable to lightning effects as a result of their lower thermal and electrical conductivities when compared to metallic structures. For that reason, important steps of lightning protection specifications and certification processes must be realized. ${ }^{3}$ Those processes are accomplished mainly through lightning laboratory tests, which deal with high current waveforms higher than $100 \mathrm{kA}$ peak. ${ }^{4}$

Lightning electrical arcs produce air plasmas with high temperature and high pressure. For instance, for a waveform of $100 \mathrm{kA}$ peak, the plasma can reach temperatures and pressures higher than $40000 \mathrm{~K}$ and $5 \mathrm{MPa}$, respectively. At the impact point region, the arc imposes important thermal 
constraints to the aeronautical material which causes a significant increase of the local temperature, and can lead to melting, puncture and delamination. ${ }^{5}$ In the aeronautical context, some studies have dealt with the arc-electrode interaction for air plasmas. Chemartin et al. ${ }^{6}$ have studied the interaction of the electrode and DC electrical arcs in air, ranging from 200 to 600 A. Many other works have dealt with the energy balance at the arc-electrode interface for a variety of arc applications as, for instance, welding, cutting, circuit-breakers, furnaces, high-intensity discharge (HID) lamps, etc. ${ }^{7-20}$ To mention a few examples, Benilov et al. ${ }^{7-10}$ have performed many studies on the modelling of plasma-electrode interaction in HID lamps from the earlies 90's, with current amplitudes starting from around $1 \mathrm{~A}$ to a few hundreds of amperes. Hsu et al. ${ }^{11}$, Delalondre and Simonin ${ }^{12}$, Lowke et al. ${ }^{13}$ and Lago et al. ${ }^{14}$ deal with the same category of plasma-electrode models in the context of DC arcs in argon plasmas with current ranging from 50 to $400 \mathrm{~A}$, which can be found in cutting and furnace applications. Sanders et al. ${ }^{15}$, Jonsson et al. ${ }^{16}$, Haidar ${ }^{17}$, Xu et al. ${ }^{18}$ and Rao et al. ${ }^{19}$ investigated argon arcs ranging from 100 to $400 \mathrm{~A}$ that are used for arc welding applications. Rong et al. ${ }^{20}$ studied air and air-copper mixture arcs with current amplitudes that can reach $2 \mathrm{kA}$ in low voltage circuit breakers applications. Those works proposed models for the energy transfer at the arc-electrode interface for conditions where the main mechanism is the heat flux resulting of the ions and electrons, that are accelerated in the sheath electrode region and which reach/leave the electrodes. This flux is composed of different effects which are normally treated separated. They depend on the ion and electron current density, electrode material, plasma and electrode temperature, etc. ${ }^{5-20}$ In this work, we will call this equivalent heat flux as ion-electron heat flux $q_{i-e}$.

For pulsed high current electric arcs, reaching hundreds of kA and with peak time of around ten microseconds, a simple physical picture of mechanisms present during the arc lifetime can be descripted as follows: the high electrical current that circulates in the arc column drives the main properties in the plasma. It releases electric power in the air plasma by Joule heating, which increases the plasma temperature along the entire arc column. The arc column losses a portion of this power by radiative emission and promotes the heating of the surrounding gas, helping the expansion of the column. The energy exchange source in the arc-electrode interaction can be separated in two groups. The first one is the heat flux $q\left(\mathrm{~W} \mathrm{~m}^{-2}\right)$ at the interface and the second is the volumetric power by Joule heating $P_{\text {Joule }}\left(\mathrm{W} \mathrm{m}^{-3}\right)$. Apart from possible phase change, we can assume that the heat flux is mainly composed of two major mechanisms: the ion-electron heat flux $q_{i-e}$ as a result of the electrical current flowing through the interface ${ }^{5-20}$, and the radiative flux $q_{\text {rad }}$ resulting from incoming flux from the arc column.

The aim of the present work is to investigate the energy exchanges during the arc-electrode interaction for pulsed lightning arcs up to $100 \mathrm{kA}$ (peak time of $13 \mu \mathrm{s}$ and FWHM of $40 \mu \mathrm{s}$ ) impacting metallic plates and to evaluate the contribution of the radiative flux. Rear surface temperatures are measured with infrared camera, and the heat flux at the plate interface is estimated by an inverse method. A parametric study covering current amplitude, material, plate thickness and arc polarity is performed. To analyze the contribution of the radiative transfer, calculations of the incoming radiative flux from the arc column on the plate are carried out. These computations are performed with detailed plasma spectroscopic data using a line by line calculation in association with a ray tracing method, and using time- and space-resolved temperature and pressure fields of the arc column determined experimentally.

The paper is organized as follows. Section II is dedicated to the experimental study. The current generator and the diagnostic setups utilized for high speed video imaging and Infrared-Thermography (IRT) measurements are described. We present the results of the arc current, voltage, the evolution of the root radius, the rear face temperature profiles and the total energy transferred to the plate. In 
Sec. III, we present the inverse calculation method and the procedure to obtain an estimation of the incoming flux. Section IV is devoted to the radiative transfer calculation. We describe the plasma radiative properties required in the computations, the radiative transfer geometrical solver, and then present the incident radiative flux distributions on the plate. Finally, the energy budget analyses and the influence of different mechanisms are discussed in Sec. V.

\section{Experimental investigation}

\section{A. Experimental setup and test matrix}

The lightning arc studied in this work follows the recommendations of the standards and certification processes, as described in the document SAE ARP 5412A $\mathrm{A}^{4}$. The generator is presented in detail in Refs. 21 and 22. Briefly, it is composed of four capacitors connected in parallel and discharging from a series of ballast resistances with a current return by the external structure. The switching is performed by a spark gap. One of the electrodes is the aeronautical plate and the other one is a tungsten rod with a dielectric sphere on the tip (following the recommendations of Ref. 4) to avoid a direct plasma jet from the metallic rod to the aeronautical material. The distance between the two electrodes is $120 \mathrm{~mm}$. The arc ignition is done with a thin carbon wire to avoid the increased light emission induced by a metallic wire.

In addition to voltage and current measurements, two optical diagnostics are used, IRT and high speed cameras (HSC). The IRT is performed during the arc lifetime to allow a time-resolved temperature measurement in the rear panel surface. The employed camera is a FLIR X6580 SC $(640 \times 512$ pixels, spectral range from 1.5 to $5.1 \mu \mathrm{m}$ ) which is set to operate at $750 \mathrm{fps}$ with a resolution of $200 \times 200$ pixels, and an exposure time of $90 \mu \mathrm{s}$. The IR camera is calibrated by FLIR systems and the correspondence between the measured digital level and the temperature is stored in a calibration curve. The rear panel surfaces are painted with a high emissivity matt black paint for high temperature Jelt 5771 . The thickness of the paint layer is around $25 \mu \mathrm{m}$.

Two HSCs are used to measure the shape evolution of the arc. The cameras are both Phantom V711 from Vision Research (CMOS sensor of $1280 \times 800$ pixels of $20 \mu \mathrm{m}^{2}$ ) with a resolution set to $256 \times 32$ pixels, allowing a sampling rate of $500 \mathrm{kfps}$, with an exposure time of $0.3 \mu \mathrm{s}$. Figure 1(a) shows a picture of the experimental setup with the current generator, the impacted plate and the optical diagnostics, and Fig. 1(b) present a schematic diagram of the electrodes and the arc zone.

(a)

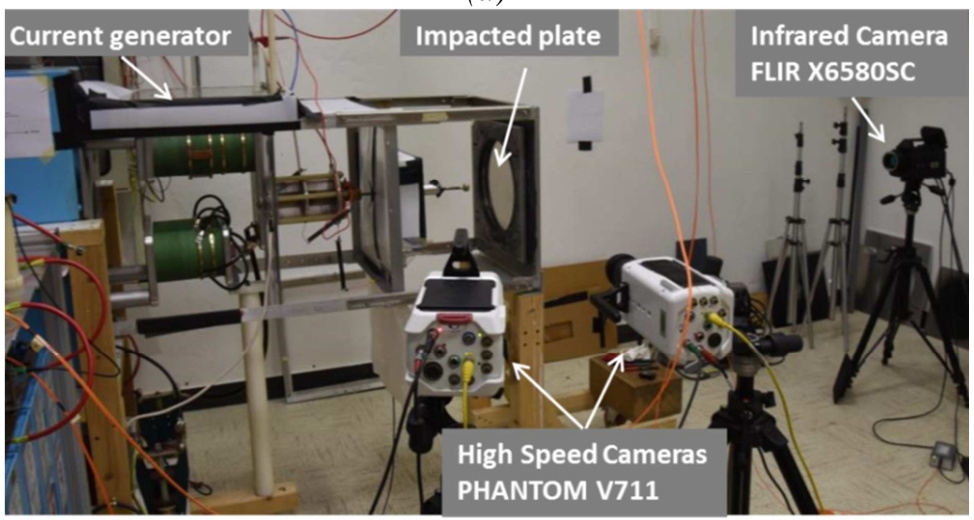

(b)

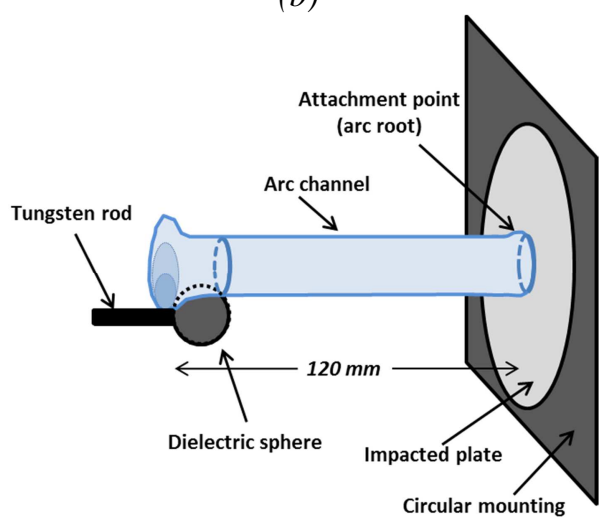

FIG. 1. (a) Picture of the experimental setup and (b) diagram of the electrodes and arc zone. 
A parametric study is carried out for four parameters: plate material, current amplitude, discharge polarity and panel thickness. Concerning the material, we simplified the study by using only metallic plates instead CFRP materials, in order to have isotropic and reliable properties for the thermal diffusion modelling, necessary to solve the problem by inverse method. A preliminary study has shown that, for an aluminum plate (aeronautical alloy Al 2024-T3), the melting temperature $\left(T_{\text {melt }}=\right.$ $933.47 \mathrm{~K}$ ) can be reached at the arc-plate interface (attachment point). Therefore, in addition to aluminum, two other materials were used to avoid reaching the melting temperature: titanium with $T_{m e l t}$ at $1941 \mathrm{~K}$ and tungsten with $T_{m e l t}$ at $3695 \mathrm{~K}$. The polarity of the discharge (the impacted plate being the cathode or the anode), as well as the current amplitude, are expected to modify the electrode voltage fall $(E V F)$. The amplitude will be the only parameter that will affect the incoming radiative flux, modifying the intensive thermodynamic properties of the arc column (temperature and pressure fields inside the arc column). Varying the thickness of the plate allows us to act on the sensitivity of the thermal measurement (maximum temperature reached) and on the diffusion time. A total of 18 configurations are tested. The test matrix is summarized in Table I. A negative polarity in this table means that the panel is the anode. The samples are square plates of $400 \times 400 \mathrm{~mm}^{2}$, clamped at the generator structure with a circular mounting.

TABLE I. Test matrix.

\begin{tabular}{rlcccc}
\hline \hline test & specimen & $\begin{array}{c}\text { thickness } \\
(\mathbf{m m})\end{array}$ & $\begin{array}{c}\text { Ipeak } \\
(\mathbf{k A})\end{array}$ & polarity & notation \\
\hline T1 & Aluminum & 0.8 & 50 & + & Al_0.8_50+ \\
T2 & Aluminum & 1.6 & 50 & + & Al_1.6_50+ \\
T3 & Aluminum & 0.8 & 100 & + & Al_0.8_100+ \\
T4 & Aluminum & 1.6 & 100 & + & Al_1.6_100+ \\
T5 & Aluminum & 1.6 & 100 & + & Al_1.6_100+b \\
T6 & Titanium & 0.8 & 50 & + & Ti_0.8_50+ \\
T7 & Titanium & 1.2 & 50 & + & Ti_1.2_50+ \\
T8 & Titanium & 0.8 & 100 & + & Ti_0.8_100+ \\
T9 & Titanium & 1.2 & 100 & + & Ti_1.2_100+ \\
T10 & Titanium & 1.2 & 100 & + & Ti_1.2_100+b \\
T11 & Tungsten & 1.0 & 100 & + & W_1.0_100+ \\
T12 & Tungsten & 1.0 & 50 & + & W_1.0_50+ \\
T13 & Tungsten & 1.0 & 100 & + & W_1.0_100+b \\
T14 & Tungsten & 1.0 & 100 & - & W_1.0_100- \\
T15 & Aluminum & 0.8 & 50 & - & Al_0.8_50- \\
T16 & Aluminum & 1.6 & 50 & - & Al_1.6_50- \\
T17 & Aluminum & 0.8 & 100 & - & Al_0.8_100- \\
T18 & Aluminum & 1.6 & 100 & - & Al_1.6_100- \\
\hline \hline
\end{tabular}


For the three different materials, the density $(\rho)$, the specific heat capacity $\left(C_{p}\right)$, the melting temperature $\left(T_{m e l t}\right)$ and the thermal conductivity $(k)$ are taken from Ref. 23 for aluminum alloy AL 2024-T3, from Ref. 24 for titanium, and from Ref. 25 for tungsten. Temperature dependence is taken into account for $k$, while $\rho$ and $C_{p}$ are assumed constant. A second degree polynomial expression, fitting the data taken from Refs. $23-25$, is used to calculate $k(T)$ from $300 \mathrm{~K}$ to $T_{\text {melt }}$. Table II summarizes the material properties employed in this work.

TABLE II. Thermal properties of the studied materials.

\begin{tabular}{|c|c|c|c|c|c|}
\hline \multirow{2}{*}{ specimen } & \multirow{2}{*}{$\begin{array}{r}\text { Density } \\
\left(\mathrm{kg} \mathrm{m}^{-3}\right)\end{array}$} & \multirow{2}{*}{$\begin{array}{c}\text { Specific } \\
\text { heat } \\
\text { capacity } \\
\left(\mathrm{J} \mathrm{kg}^{-1} \mathbf{K}^{-1}\right)\end{array}$} & \multirow{2}{*}{$\begin{array}{c}\begin{array}{c}\text { Melting } \\
\text { temperature }\end{array} \\
\text { (K) }\end{array}$} & \multicolumn{2}{|c|}{$\begin{array}{l}\text { Thermal conductivity versus temperature } \\
\qquad\left(\mathrm{W} \mathrm{m} \mathbf{m}^{-1} \mathrm{~K}^{-1}\right)\end{array}$} \\
\hline & & & & $\begin{array}{c}\text { average } \\
(300 K \text { to } \\
\left.T_{\text {melt }}\right)\end{array}$ & $\begin{array}{c}\text { Applied expression } k(T) \\
\text { (polynomial approximation) }\end{array}$ \\
\hline \multicolumn{6}{|l|}{ Aluminum } \\
\hline $\begin{array}{l}(\mathrm{AL} \mathrm{2024-} \\
\mathrm{T} 3)^{-}\end{array}$ & 2780 & 875 & 933.5 & 175.4 & $-1.133 \times 10^{-4} \times \mathrm{T}^{2}+0.296 \times \mathrm{T}+39.15$ \\
\hline Titanium & 4510 & 523 & 1941.15 & 22 & $6.26 \times 10^{-6} \times \mathrm{T}^{2}-0.009 \times \mathrm{T}+23.10$ \\
\hline Tungsten & 19300 & 132 & 3695.15 & 107.3 & $1.133 \times 10^{-5} \times \mathrm{T}^{2}-0.063 \times \mathrm{T}+178.8$ \\
\hline
\end{tabular}

\section{B. Arc current, voltage and root radius}

Figure 2 presents the measurements of the two pulsed current waveforms and the corresponding total arc voltage, studied in this work. For the current peak of $50 \mathrm{kA}$, the peak time and the current slope at the arc ignition $(\mathrm{t}=0)$ are, respectively, $12.6 \mu \mathrm{s}$ and $8.4 \mathrm{kA} \mathrm{\mu s}^{-1}$. For the $100 \mathrm{kA}$ waveform, these parameters are equal to $12.3 \mu \mathrm{s}$ and $19.5 \mathrm{kA} \mathrm{\mu s}^{-1}$. For both waveforms, the FWHM is around $40 \mu \mathrm{s}$ with approximately $85 \%$ of the electric charge transferred in the first $100 \mu \mathrm{s}$ and the total current close to zero after $300 \mu \mathrm{s}$. The repeatability of this current waveform was evaluated in previous studies and for the $100 \mathrm{kA}$ case, it has a standard deviation of $0.3 \mathrm{kA} .{ }^{21}$ The total arc voltage, obtained by the voltage difference between the two electrodes, falls by one order of magnitude in the first twenty microseconds as the current in the arc increases. After approximately $30 \mu \mathrm{s}$, this voltage reaches a steady level with values of $620 \mathrm{~V}$ for $50 \mathrm{kA}$ and $440 \mathrm{~V}$ for $100 \mathrm{kA}$. 
(a)

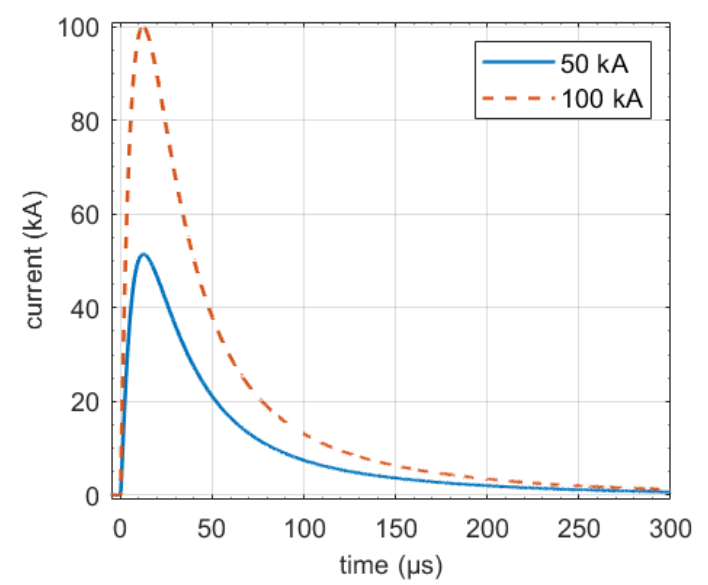

(b)

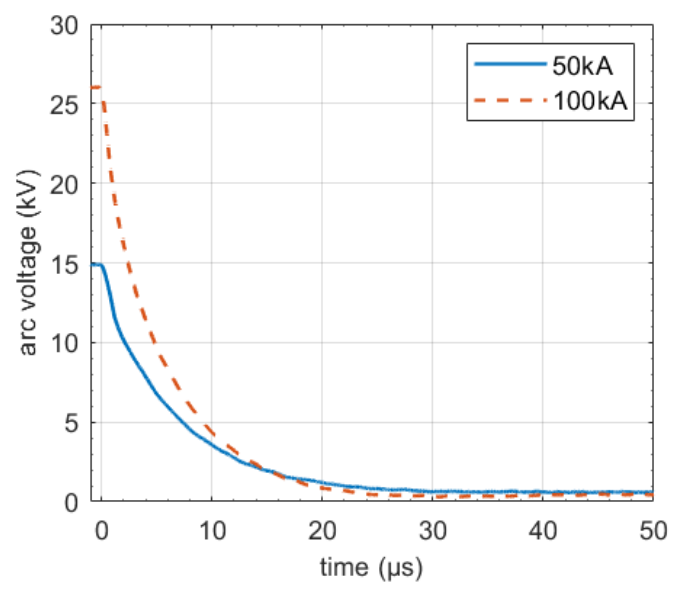

FIG. 2. Studied current waveforms $(a)$ and the corresponding total arc voltage $(b)$.

During the first $60 \mu \mathrm{s}$, the arc column expands in the radial direction showing an axisymmetric shape. The arc root (the portion of the arc channel in the vicinity of the electrode) follows this axisymmetric expansion with a small constriction effect due to the plate presence. ${ }^{22}$ Figure 3 presents a few pictures of the arc root recorded by HSC. The arc root radius evolution is deduced from the radial profile obtained by HSC measurements and based on both derivative of light intensity and threshold criteria, as described in Refs. 14 and 15. The radial profiles are analyzed between 0.75 to $1.25 \mathrm{~mm}$ from the plate surface, which includes three rows of pixels in a picture. The results for the arc root evolution are based on one shot per configuration, while the free column is obtained by an average of around 50 tests.



FIG. 3. Pictures of the arc root zone for a $100 \mathrm{kA}$ waveform applied to an aluminum plate. The material is located at the bottom of each image.

Figure 4 presents the results for different materials at the two current amplitudes. All arc roots are slightly smaller than the free column, showing a constriction effect as observed in Fig. 3. The maximum radii are around $20 \mathrm{~mm}$ for $50 \mathrm{kA}$ waveforms, and $28 \mathrm{~mm}$ for $100 \mathrm{kA}$. The root radius for aluminum plates is approximately $8 \%$ higher than for titanium and tungsten. A similar difference is 
also observed for the positive polarity when compared to the negative one. The panel thickness seems to not affect the root radius.

(a)

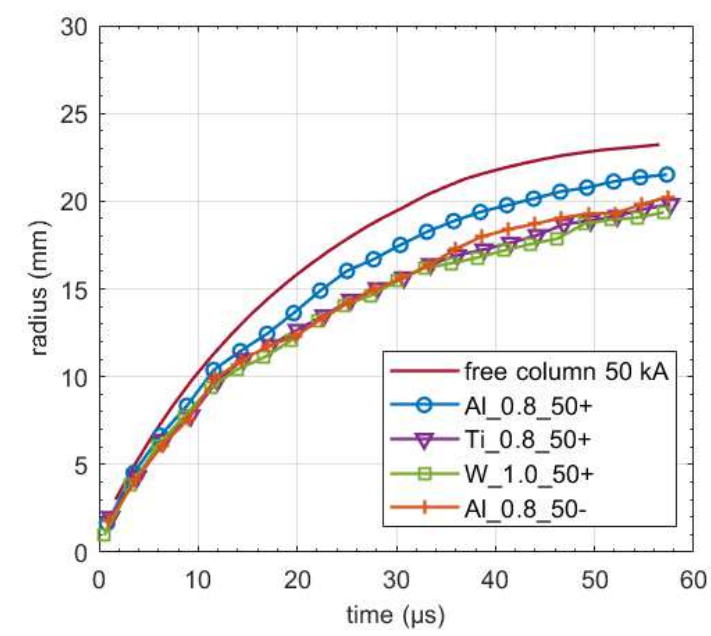

(b)

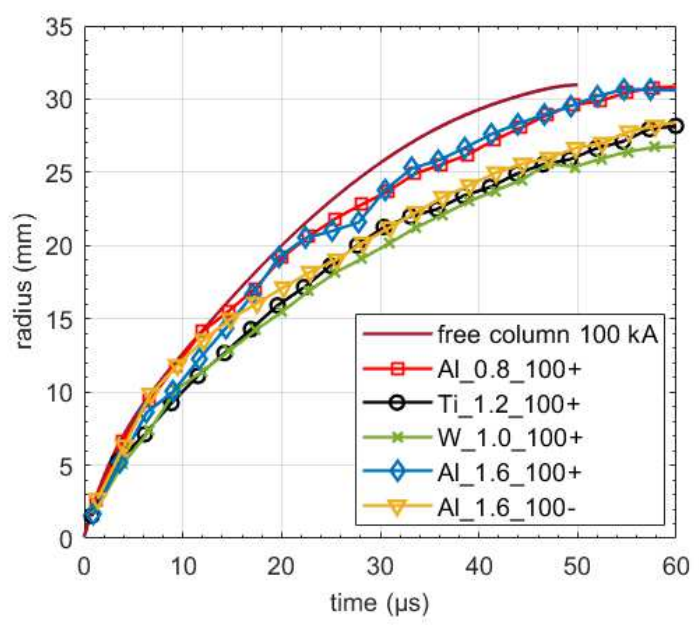

FIG. 4. Arc root evolution for (a) $50 \mathrm{kA}$ and (b) $100 \mathrm{kA}$.

\section{Examination of the surface damage}

The evaluation of the plate surface after the lightning arc can provide a few insights of the arc-material interaction. Figure 5 shows the pictures of the attachment point after an arc test for different plates. Generally, the spots exhibit a circular shape with similar sizes. They are slightly higher for the tungsten compared to the others materials. The diameters of the spots are around $25 \mathrm{~mm}$ for $50 \mathrm{kA}$ and $30 \mathrm{~mm}$ for $100 \mathrm{kA}$, which corresponds approximately to their respective arc root diameter at the current peak. A few asymmetries are observed for the cases of $100 \mathrm{kA}$ arc in positive polarity for aluminum and titanium (plate being the cathode), where a radial streak is noticed. This inhomogeneity is also observed with the IRT measurements (see Sec. II.D), and this seems to be related to the ignition phase of the ignition wire. A few colorful marks are observed at the surface, in the vicinity of the attachment point. These marks seem to be a thin deposition originated from some vaporization or from the high temperatures reached at the attachment region, and can be easily removed if we gently clean the surface. For aluminum and titanium plates, a small area in the center of the spot appears to reach a phase change. More details about this phase change and the area that can reach melting temperature are discussed in Sec. III.B. 

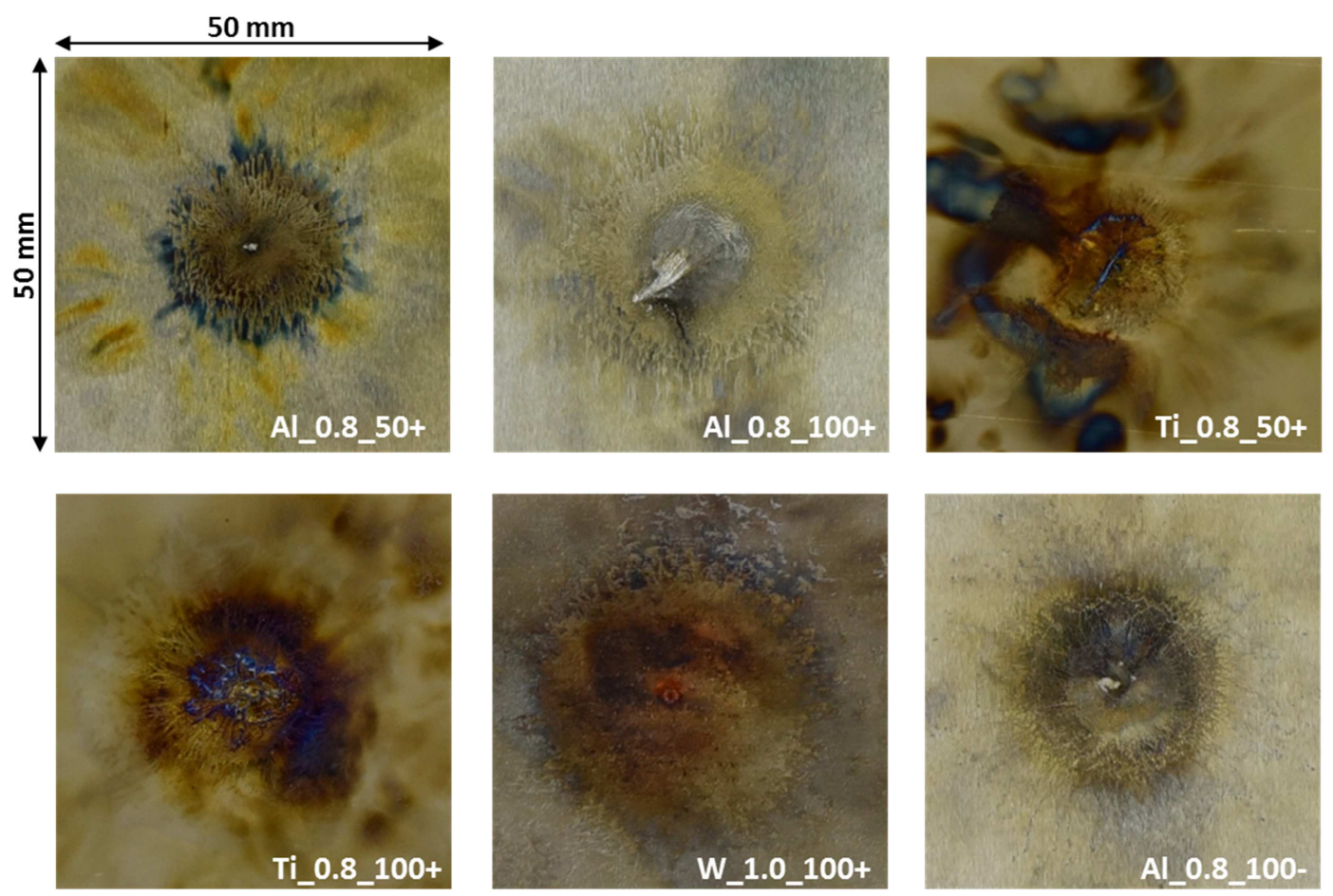

FIG. 5. Plate surface damages after shot.

\section{IRT measurements and analysis}

The IRT measurements of the rear plate surface temperature are performed with a frequency of $750 \mathrm{~Hz}$, leading to a period of $1.33 \mathrm{~ms}$. As presented in Sec. II.B, the arc characteristic time is around $100 \mu \mathrm{s}$, which means that the first IR camera acquisition takes place after the end of the arc. However, the conductive time scales $\tau_{c}$, given by $\tau_{c}=e^{2} / a$, with $e$ being the plate thickness and $a$ the thermal diffusivity, given by $a=k /\left(\rho C_{p}\right)$, are higher than $10 \mathrm{~ms}$ for the studied plates. Therefore, the IRT sampling rate is enough to well describe the increase of rear plate temperature.

Figure 6 shows an example of the measured rear surface temperature for the case Al_0.8_100+ at different instants. This case was chosen because it shows the most asymmetric temperature distribution among the studied configurations. At $4 \mathrm{~ms}$, the radial streak observed on the incident side (Fig. 5) is well identified. After a few milliseconds, the radial diffusion starts to create an axisymmetric distribution. At $100 \mathrm{~ms}$, the spot is already well symmetric, and as we observe by the isothermal contour lines at $500 \mathrm{~ms}$, the surface temperature exhibits a fully axisymmetric distribution.

For analysis purposes and to solve the inverse problem with a simpler method, an axisymmetric hypothesis is considered. So, a radial profile is calculated from the surface temperature distribution. The spot center is defined using the measurement at a few hundreds of milliseconds. This center point is used to calculate a radial mean profile. Two examples are presented in Fig. 7. As expected, we observe that at $4 \mathrm{~ms}$ the mean radial profile shows a few oscillations due to the original form, but from $20 \mathrm{~ms}$ the mean profile exhibits a smooth profile along the radius. In both examples, there is a temperature increase phase, reaching a maximum higher than $460 \mathrm{~K}$ for Al_0.8_100+ and $400 \mathrm{~K}$ for W_1.0_100+ tests. After the maximum value, the characteristic length of the profiles, as for instance the half width at half maximum (HWHM), is around $15 \mathrm{~mm}$, which corresponds to the damage size observed in Fig. 5. 

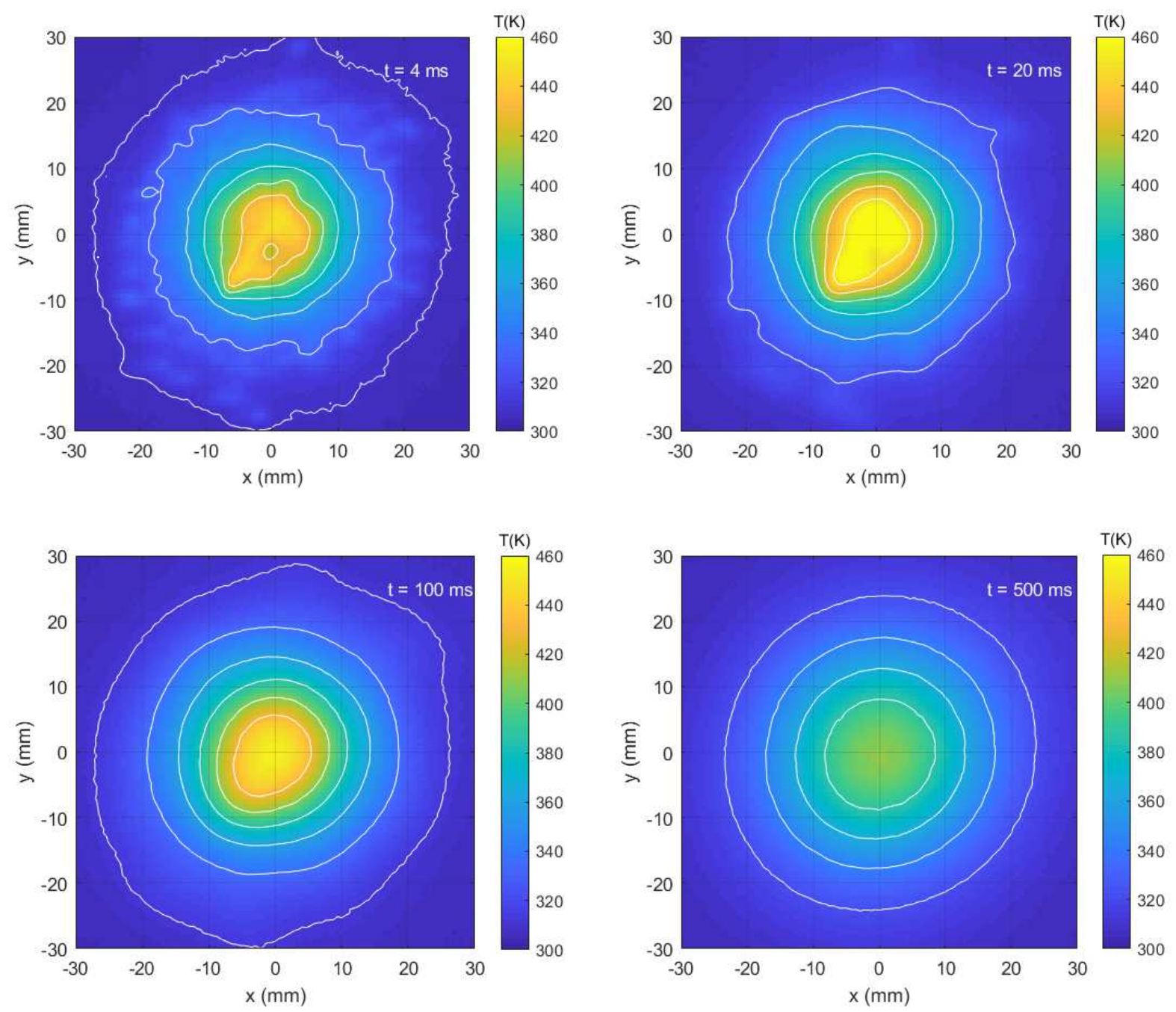

FIG. 6. Examples of the rear temperature measurements with a few isothermal contour lines for Al_0.8_100+ test at different instants $(4,20,100$ and $500 \mathrm{~ms})$.

(a)

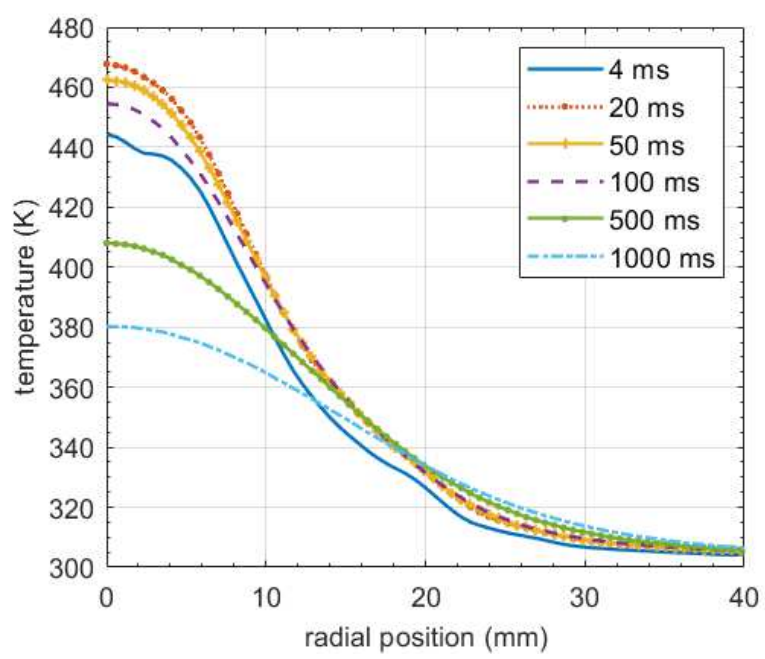

(b)

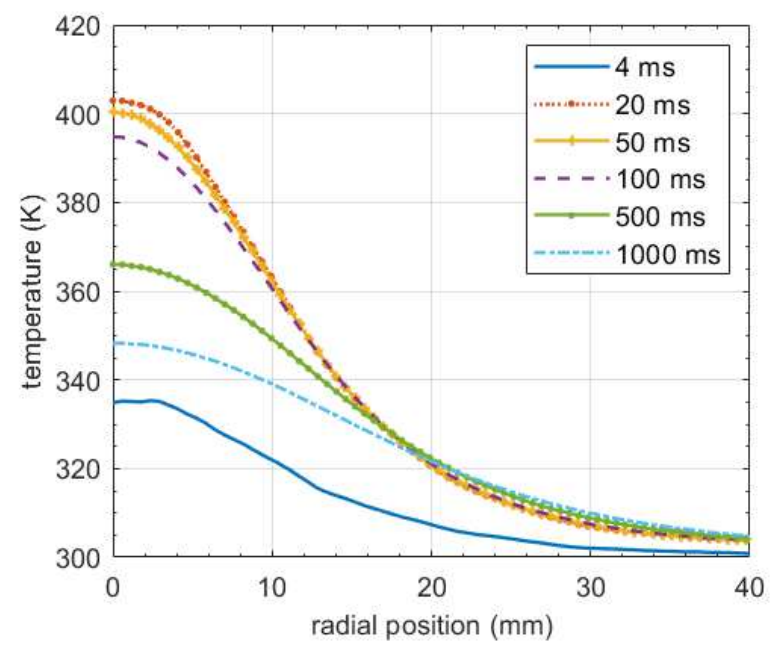

FIG. 7. Examples of radial mean profiles for two shots: (a) Al_0.8_100+ and (b) W_1.0_100+. 
To give a general idea of temperature evolution for the tested configurations, we can plot the center temperature over time, obtaining a function $T(t)$. The studied configurations have very different ranges of temperature and conductive time scales $\left(\tau_{c}\right)$. So, this function is normalized, using a nondimensional temperature $T^{+}$, given by $T^{+}=\left(T-T_{0}\right) /\left(T_{\max }-T_{0}\right)$, with $T_{0}$ and $T_{\max }$ being, respectively, the initial and maximum temperature for each configuration, and a non-dimensional time $t^{+}$, given by the Fourier number $t^{+}=a t / e^{2}$. The results of the non-dimensional function $T^{+}\left(t^{+}\right)$, are presented in Fig. 8 , for several configurations. The non-dimensional curves show a very good similarity during the initial growth rate and until the peak time, with all maximum $T^{+}$being reached before $t^{+}=1$ for all cases. For the curve evolution after the maximum, in addition to the heat conductive effects, the temperature decay depends also on convective and radiative losses. These losses depend on the absolute temperature and material properties that are not taken into account by the non-dimensional function, resulting in different behaviors during the cooling stage for different configurations.

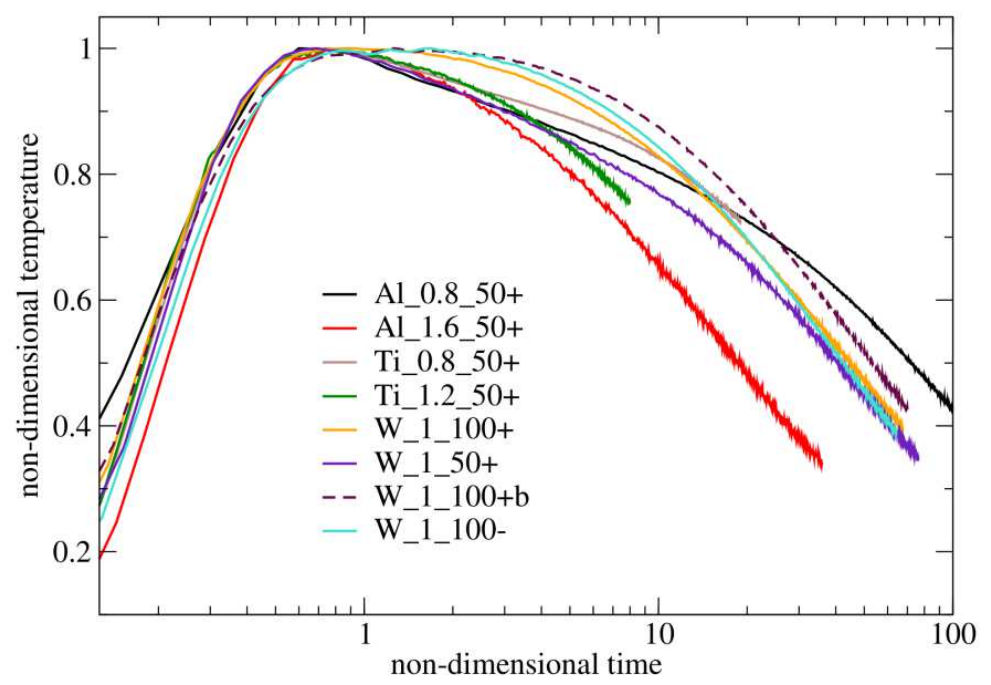

FIG. 8. Non-dimensional center temperature versus non-dimensional time for different tested configurations.

The rear surface temperature measurement can be also used to estimate the total stored energy transferred to the plate. Assuming that at each instant $t$, the temperature is uniform in the plate thickness, we can calculate the cumulated transferred energy by:

$$
\Delta E(t)=\int_{S} e \rho C_{p}\left(T(t)-T_{0}\right) d S
$$

The results for some test cases are presented in Fig. 9. We can observe that for the same material and current amplitude, the maximum reached by $\Delta E$ is approximately identical, with values around $150 \mathrm{~J}$ for $50 \mathrm{kA}$ and $300 \mathrm{~J}$ for $100 \mathrm{kA}$, in the case of aluminum plates. This energy reached $330 \mathrm{~J}$ for the tungsten sample. Notice that the hypothesis of a uniform temperature in the thickness of the plate is not valid in the first milliseconds, when the temperature of the front face is much higher than the rear face one since the conductive time $\tau_{c}$ is of the order of $10 \mathrm{~ms}$ for those configurations. For that reason, the result given by Eq. 1 continuously increases during this period, even though the arc characteristic time is much smaller, of the order of $100 \mu$ s. However, as, in addition, heat losses by convection and radiation can be neglected in these first milliseconds, the maximum energy given by the maximum of Eq. 1 over time represents a lower bound but is very close to the real transferred energy. Table III 
(described in Sec. III) will summarize the maximum stored energy, maximum temperature and the characteristic times for all configurations.

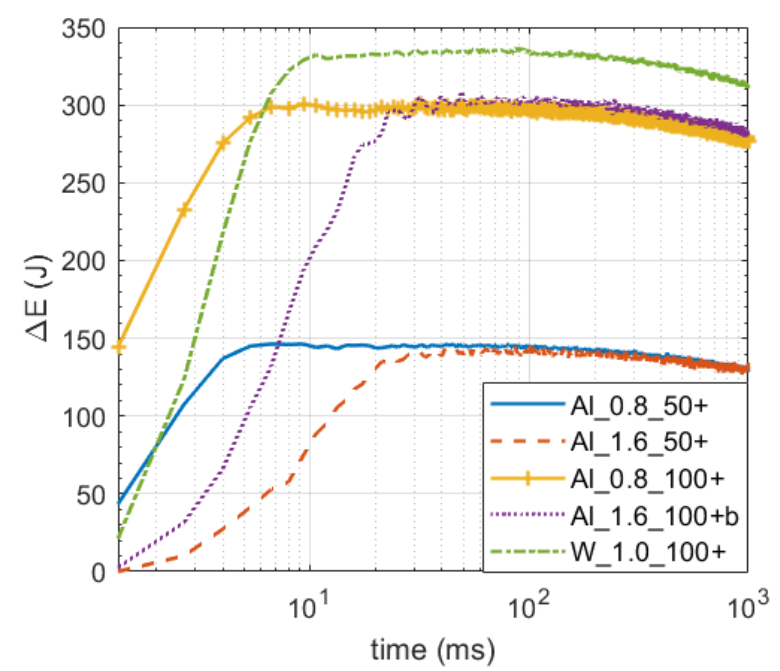

FIG. 9. Stored energy transferred to the plate for different configurations.

Two tests are performed to verify the uncertainty and repeatability of the IRT measurements. Figure 10 present the temperature profile difference between configurations with identical parameters for aluminum and tungsten plates. For aluminum, the differences remain smaller than $3 \mathrm{~K}$, which corresponds to less than $2 \%$ of the temperature variation. For tungsten the difference reaches $6 \mathrm{~K}$ around the maximum temperature, equivalent to a discrepancy of $6 \%$.

(a)

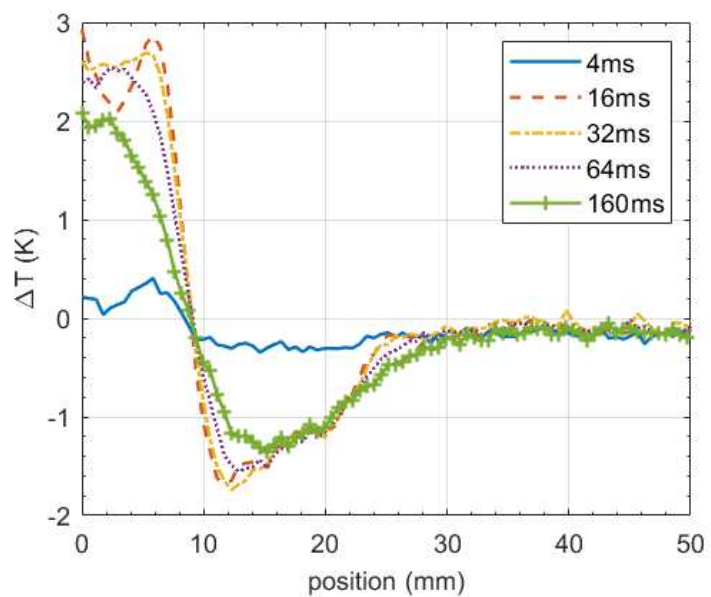

(b)

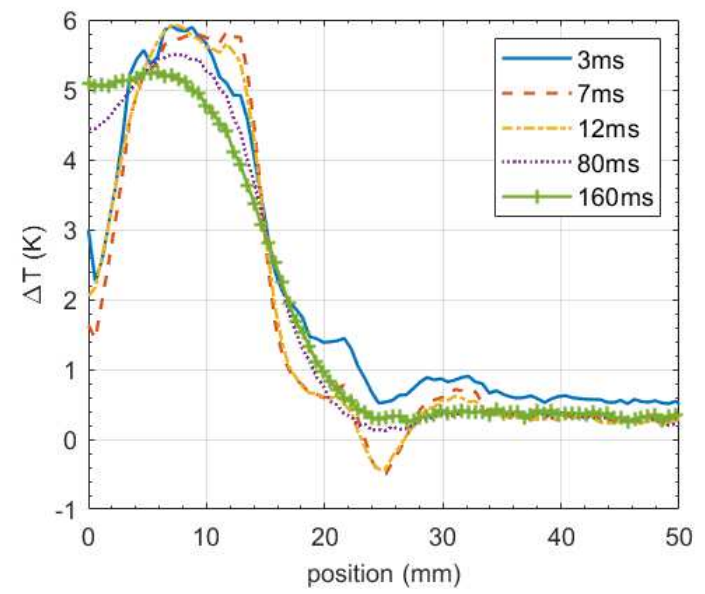

FIG. 10. Temperature difference between tests with identical parameters at different instants:

(a) comparison Al_1.6_100+ with Al_1.6_100+b and (b) comparison W_1.0_100+ with W_1.0_100+b.

\section{Inverse method and analysis}

\section{A. Problem statement and assumption}

The direct problem, with the heat flux $(q)$ imposed at the arc attachment point and leading to an increase of the temperature in the plate, is solved using the heat diffusion equation and taking into account the volumetric Joule heating. The equation is given by: 


$$
\rho C_{p} \frac{\partial T}{\partial t}=\vec{\nabla} \cdot(k \vec{\nabla} T)+P_{\text {joule }}
$$

The problem is discretized in a 2D-axisymmetric geometry and is solved using a finite volume Euler explicit scheme, with second order accuracy for space. The plate is supposed to be a homogenous disc with thickness $e$ and radius $R=200 \mathrm{~mm}$. The temperature $T$ is calculated as a function of radial position $r$, axial position $z$ ( $z=0$ corresponding to the impacted surface) and time $t$. The boundary conditions are:

$$
\left\{\begin{array}{c}
T(r, z, t=0)=T_{0} \\
T(r=R, z, t)=T_{0} \\
-k \partial T(r, z=0, t) / \partial z=q(r, t)-h_{i n}\left(T-T_{0}\right)-\varepsilon_{i n} \sigma\left(T^{4}-T_{0}^{4}\right) \\
-k \partial T(r, z=e, t) / \partial z=h_{r e}\left(T-T_{0}\right)+\varepsilon_{r e} \sigma\left(T^{4}-T_{0}^{4}\right)
\end{array}\right.
$$

where $\sigma, h$ and $\varepsilon$ are respectively the Stefan-Boltzmann constant, the heat transfer coefficient and the surface emissivity. The subscripts "in" and " $r e$ " denote incident and rear surfaces. The terms, with $h$ and $\varepsilon$, account for convection and radiative losses, respectively. The heat transfer coefficient is taken as $10 \mathrm{~W} \mathrm{~m}^{-2} \mathrm{~K}^{-1}$ for both surfaces, and the emissivity is set to 0.3 for incident and 1 for rear surfaces. These parameters have no significant effects on the results at short time scales, heat losses being very weak compared to the heat fluxes induced by the electrical arc.

The axial position $z$ is discretized into $n_{z}=40$ uniformly distributed values. To be more sensitive near the attachment point, the radial direction is discretized in $n_{r}=200$ non-uniformly distributed points, following an arctangent expression, with the step size at the axis equal to $0.47 \mathrm{~mm}$ and at the plate edge equal to $1.52 \mathrm{~mm}$. The time step is equal to $1 \mu \mathrm{s}$ for the first $500 \mu \mathrm{s}$, to take into account the variations of the incident heat flux during a few arc characteristic times, and then it increases to $5 \mu \mathrm{s}$ until the end of the calculation.

The volumetric Joule heating at each time $t$ is calculated assuming an electrostatic potential distribution $V^{t}(r, z)$ over the material, which is obtained by solving the Poisson equation, $\vec{\nabla} .\left(\sigma_{e} \vec{\nabla} V^{t}\right)=0$, where $\sigma_{e}$ is the electrical conductivity of the material. The Joule power is then obtained by $P_{\text {Joule }}=\sigma_{e}\left|\nabla V^{t}\right|^{2}$. The Poisson equation is solved by a finite volume Euler implicit scheme, with boundary conditions given by $-\sigma_{e} \partial V^{t}(r, z=0) / \partial z=j^{t}(r), \partial V^{t}(r=0, z) / \partial r=\partial V^{t}(r, z=e) / \partial z=0$ and $V^{t}(r=R, z)=0$, where $j^{t}(r)$ is the current density at the attachment point at time $t$. The current density is calculated using the measured total current and assuming a Gaussian radial distribution with the standard deviation given by the measured arc radius $r_{a r c}(t)$.

To solve the inverse problem, we impose a candidate function for the total incident flux $q(r, t)$, and then we calculate the direct problem to obtain the temperature $T(r, z, t)$. The calculated rear plate temperature is compared to the measured one and a least-square procedure is applied to adjust the parameters defining the candidate function of the incident flux.

First tests were performed with only one total incident flux, having a Gaussian distribution in space and a bi-exponential evolution in time. However, the adjustment was poor with only one spatial and temporal constant. Improved results are obtained with two independent density fluxes, modelled by $q_{1}(r, t)$ and $q_{2}(r, t)$ as given by: 


$$
\begin{aligned}
& q_{1}(r, t)=p_{1}\left(\exp \left(-\frac{t}{\tau_{11}}\right)-\exp \left(-\frac{t}{\tau_{12}}\right)\right) \frac{\sqrt{2}}{\pi^{3 / 2}\left(\alpha_{1} r_{a r c}(t)\right)^{2}} \exp \left(-\frac{1}{2}\left(\frac{r}{\alpha_{1} r_{\text {arc }}(t)}\right)^{4}\right) \\
& q_{2}(r, t)=p_{2}\left(\exp \left(-\frac{t}{\tau_{21}}\right)-\exp \left(-\frac{t}{\tau_{22}}\right)\right) \frac{1}{2 \pi\left(\alpha_{2} r_{\text {arc }}(t)\right)^{2}} \exp \left(-\frac{1}{2}\left(\frac{r}{\alpha_{2} r_{\text {arc }}(t)}\right)^{2}\right)
\end{aligned}
$$

where $p_{i}, \tau_{i 1}$ and $\tau_{i 2}$ are the coefficients that describe the bi-exponential function for the temporal evolution and $\alpha_{i}$ is a coefficient applied to the arc radius to allow some flexibility of the radial distributions $(i=1$ or 2$)$. In order to allow two different shapes for the spatial profile, a super Gaussian function of order four is used for the distribution of $q_{1}$, which gives a sharp shape for the profile. A Gaussian function is used to model $q_{2}$. The radial deviation for both profiles is estimated by the product of their respective coefficient $\alpha_{i}$ and the arc radius. In total, four parameters for each heat flux are used in the minimization of the least-square procedure, namely $p_{i}, \tau_{i l}, \tau_{i 2}$ and $\alpha_{i}$. The comparisons are performed over all points in the measured radial profile ( 135 points) and from times from 1.33 to $500 \mathrm{~ms}$. Same results of the adjusted parameters were also obtained when limiting the calculation time to $160 \mathrm{~ms}$. Integrating each surface flux $q_{i}$ over the surface, we obtain the corresponding total flux:

$$
P_{i}(t)=\int_{0}^{R} q_{i}(r, t) 2 \pi r d r=p_{i}\left(\exp \left(-\frac{t}{\tau_{i 1}}\right)-\exp \left(-\frac{t}{\tau_{i 2}}\right)\right)
$$

and, by integrating over time this total flux, the dissipated energy is deduced:

$$
E_{i}=\int_{0}^{t_{\text {end }}} P_{i}(t) d t
$$

where $t_{\text {end }}$ is a long time compared to the arc characteristic time, of the order of a few milliseconds. For the cases when melting temperature is reached inside a cell, the temperature of the affected cell is blocked at $T_{\text {melt }}$ until the next time step. This limitation can last for several time steps, and this temperature is naturally decreased when the conductive flux to adjacent cells is higher than the incoming flux.

\section{B. Results and analyses}

The inverse method is applied to all 18 tested configurations. In ten cases, the melting temperature was reached at the incident face. These cases correspond to aluminum and titanium plates with $100 \mathrm{kA}$ current in both polarities and also to aluminum with $50 \mathrm{kA}$ in negative polarity. The duration that the temperature remains at $T_{\text {melt }}$ varies from approximately $20 \mu \mathrm{s}$, for $50 \mathrm{kA}$ cases, to $150 \mu \mathrm{s}$ for $100 \mathrm{kA}$. Nevertheless, the area concerned by the melting is a small disc, ranging from 2 to $7 \mathrm{~mm}$ radius. A calculation was performed to compare the incoming energy provided by the imposed energy flux $\left(E_{1}+\right.$ $\left.E_{2}\right)$ and the energy transferred to the whole plate by conduction when melting was detected. This energy is obtained according to: 


$$
E_{c d}=\int_{0}^{t_{\text {end }}} \int_{0}^{R}-\left.k \frac{\partial T}{\partial z}\right|_{z=0} 2 \pi r d r d t
$$

For the Al_0.8_100- test, for instance, the difference between $E_{1}+E_{2}$ and $E_{c d}$ is smaller than $6 \mathrm{~J}$, which corresponds to less than $2 \%$ of the total transferred energy.

Figure 11 presents examples of the measured and calculated radial temperature profiles. A good agreement is found, and discrepancies of less than $4 \mathrm{~K}$ are observed, which corresponds to less than $4 \%$ when compared to the absolute variation from the initial temperature.

(a)

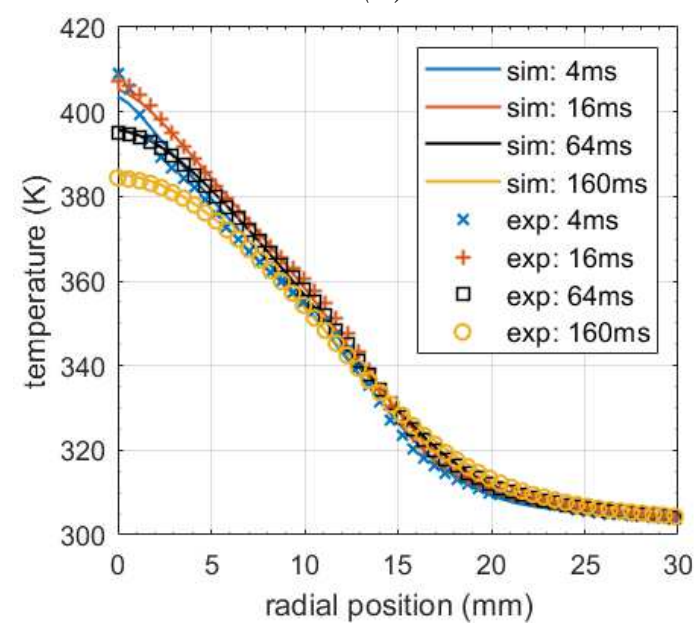

(c)

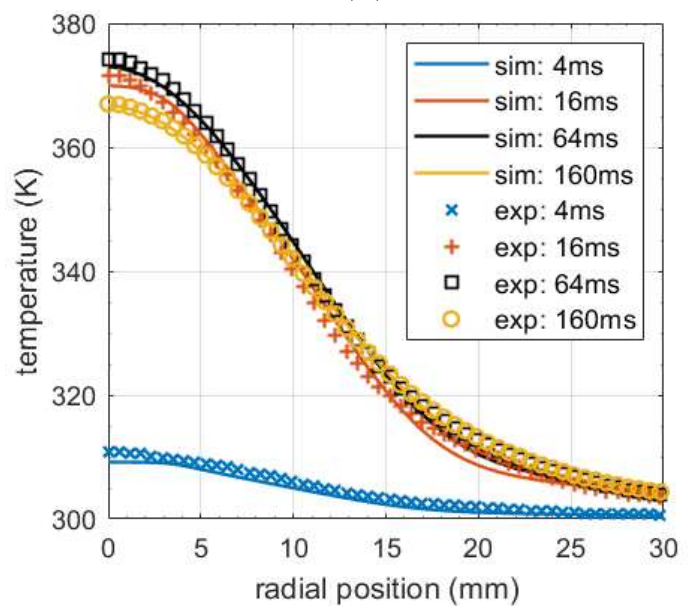

(b)

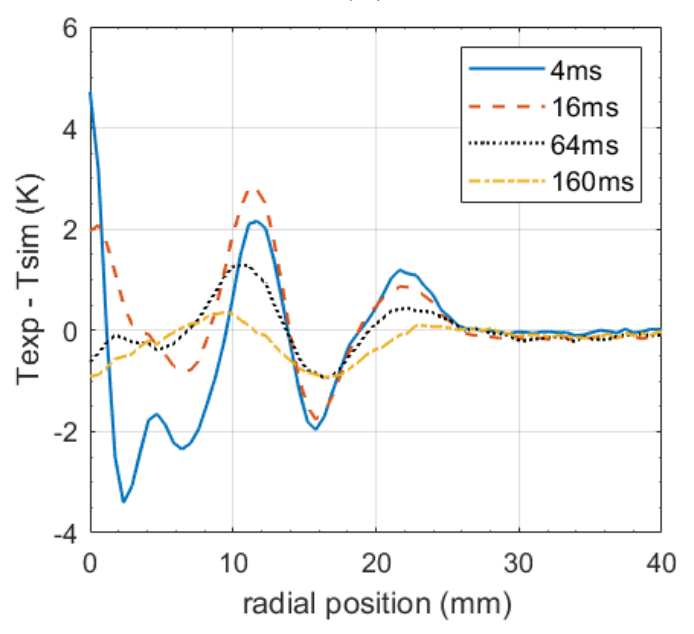

(d)



FIG. 11. (a) Adjustment and (b) difference of measured (exp) and simulated (sim) temperatures for case Al_0.8_50+. (c) Adjustment and (d) difference of measured and simulated temperatures for case Al_1.6_100+.

Figure 12 illustrates two examples of the obtained total fluxes over time, $P_{l}$ and $P_{2}$, from the inverse method. For the case of $50 \mathrm{kA}$, the characteristic times are similar for both curves, and consequently the total incoming energy for each flux is comparable, with values around $70 \mathrm{~J}$. On the other hand, for 
$100 \mathrm{kA}$, there is an important difference in the shape of the curves, and the incoming energy is twice higher for $q_{2}$ reaching $170 \mathrm{~J}$. The adjusted radius coefficients $\alpha_{i}$ are in most cases less than 1, which indicates a constriction of the incident heat flux compared to the apparent arc radius presented in Fig. 4. The coefficient $\alpha_{1}$ is systematically smaller than $\alpha_{2}$. The average value for $\alpha_{1}$ is 0.33 and for $\alpha_{2}$ is 0.83 , showing that even for the cases when the temporal evolutions are comparable (Fig. 12(a)), the spatial distribution is quite different.

(a)

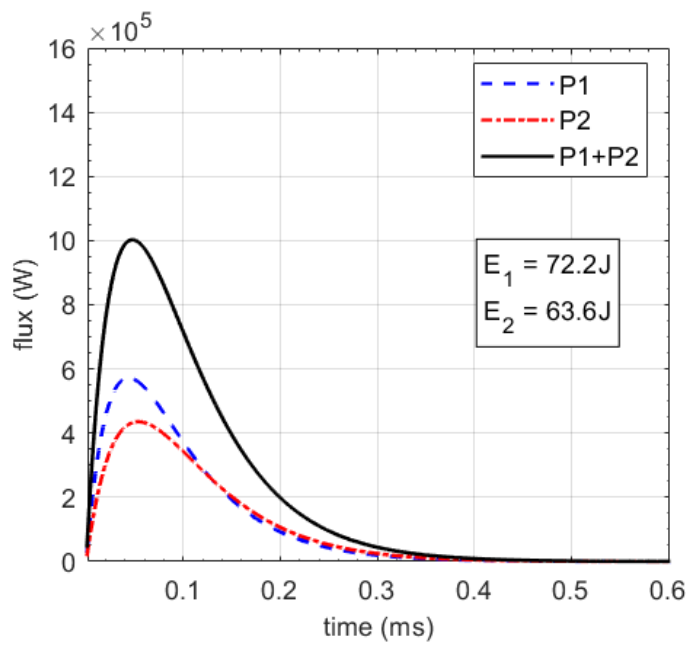

(b)

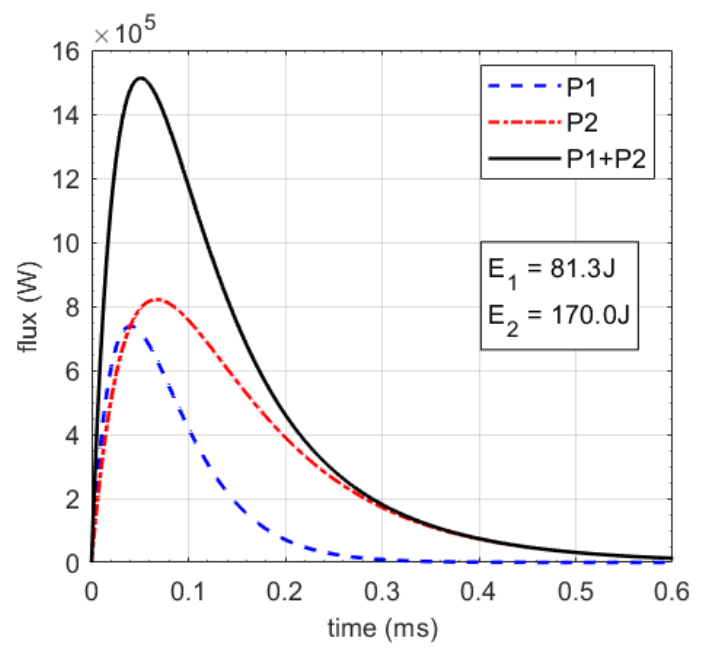

FIG. 12. Examples of surface integrated heat fluxes for $(a) \mathrm{Al} \_0.8 \_50+$ and $(b) \mathrm{Al} \_0.8 \_100+$ as determined by the inverse method.

Table III summarizes the main measured data and results of the inverse method for all tested configurations. The second and third columns present the measured transferred energy $\Delta E$ (considered as the maximum of $\Delta E(t)$ given in Eq. 1) and the maximum measured temperature reached in the rear plate surface with its corresponding peak time. The fourth column presents the maximum calculated value reached at the impacted surface. When melting temperature is reached in at least one cell, the total duration for which the temperature remains at this level is also indicated. The total incoming energies $E_{1}$ and $E_{2}$ are listed and their sum is compared to the measured $\Delta E$. The discrepancies between the measured and calculated rear temperature profiles are indicated in root mean square (RMS) error, average error $\left(e_{\text {avg }}\right)$ and maximum error $\left(e_{\max }\right)$. For two cases of titanium plates for $100 \mathrm{kA}$, the center of the temperature profile reaches saturation, as the IR camera had a limited calibration range.

A good agreement is found when comparing the measured and estimated total energy from the inverse method. Discrepancies around $12 \%$ are observed for aluminum and tungsten plates, for the different currents, thicknesses and polarities. Even for the cases of aluminum when the melting temperature is observed, the total energy is slightly affected as mentioned in Sec. III.A. Also, for aluminum and tungsten cases, the calculated temperature profiles show good results, with average errors of the order of $1 \mathrm{~K}$ and maximum errors around $6 \mathrm{~K}$. The adjustment and comparisons for titanium plates are less accurate, with average and maximum errors around $2.8 \mathrm{~K}$ and $18 \mathrm{~K}$, respectively, and energy differences that reach $55 \%$. 
TABLE III. Summary of main experimental and numerical results.

\begin{tabular}{|c|c|c|c|c|c|c|c|c|c|c|}
\hline configuration & $\Delta \mathbf{E}(\mathbf{J})$ & $\mathbf{T}_{\mathrm{c}}(\mathbf{K})$ & $\mathbf{T}_{\text {inc_max }}(\mathbf{K})$ & $\mathbf{E}_{1}(\mathbf{J})$ & $\mathbf{E}_{2}(\mathbf{J})$ & $\mathbf{E}_{\text {tot }}(\mathbf{J})$ & $\Delta \mathrm{E} / \mathbf{E}_{\mathrm{tot}}$ & $\operatorname{RMS}(\mathrm{K})$ & $\mathbf{e}_{\text {avg }}(K)$ & $\mathbf{e}_{\max }(\mathbf{K})$ \\
\hline Al_0.8_50+ & 145 & $414(7 \mathrm{~ms})$ & 880 & 63.8 & 72.2 & 136 & $7 \%$ & 0.68 & 0.33 & 4.77 \\
\hline Al_1.6_50+ & 133 & 349 (28ms) & 785 & 50.1 & 61.6 & 111.7 & $19 \%$ & 0.57 & 0.32 & 3.71 \\
\hline Al_0.8_100+ & 300 & 467 (10ms) & 933.5 for $130 \mu \mathrm{s}$ & 81.3 & 170 & 251.3 & $19 \%$ & 1.66 & 1.27 & 5.58 \\
\hline Al_1.6_100+ & 318 & 377 (29ms) & 933.5 for $24 \mu \mathrm{s}$ & 84.5 & 202 & 286 & $11 \%$ & 0.69 & 0.48 & 2.42 \\
\hline $\mathrm{Al} \_1.6 \_100+\mathrm{b}$ & 308 & $380(28 \mathrm{~ms})$ & 933.5 for $150 \mu \mathrm{s}$ & 74 & 189 & 263 & $17 \%$ & 0.67 & 0.49 & 2.39 \\
\hline Ti_0.8_50+ & 175 & $456(50 \mathrm{~ms})$ & 1794 & 86.4 & 38.4 & 125 & $40 \%$ & 2.36 & 1.36 & 14.23 \\
\hline Ti_1.2_50+ & 195 & 400 (125ms) & 1603 & 107.4 & 47.2 & 154 & $27 \%$ & 1.95 & 1.13 & 10.49 \\
\hline *Ti_0.8_100+ & 335 & $501(20 \mathrm{~ms})$ & 1941 for $25 \mu \mathrm{s}$ & 290.5 & 25 & 315.5 & $26 \%$ & 2.63 & 1.37 & 18.16 \\
\hline Ti_1.2_100+ & 330 & $472(105 \mathrm{~ms})$ & 1941 for $150 \mu \mathrm{s}$ & 223.6 & 60.9 & 285 & $16 \%$ & 2.88 & 1.93 & 19.12 \\
\hline$* \mathrm{Ti} \_1.2 \_100+\mathrm{b}$ & 360 & 473 (60ms) & 1941 for $150 \mu \mathrm{s}$ & 213 & 30 & 233 & $55 \%$ & 3.11 & 1.96 & 22.34 \\
\hline W_1.0_100+ & 330 & 403 (17ms) & 1160 & 80 & 200 & 280 & $18 \%$ & 0.99 & 0.74 & 4.40 \\
\hline W_1.0_50+ & 158 & 365 (15ms) & 700 & 66 & 78 & 144 & $10 \%$ & 0.49 & 0.30 & 2.48 \\
\hline W_1.0_100+b & 315 & 408 (19 ms) & 980 & 126.6 & 165.4 & 292 & $8 \%$ & 1.62 & 1.01 & 6.20 \\
\hline W_1.0_100- & 316 & 424 (24ms) & 1370 & 117 & 172 & 289 & $9 \%$ & 2.04 & 1.50 & 9.20 \\
\hline Al_0.8_50- & 151 & 426 (10ms) & 933.5 for $40 \mu \mathrm{s}$ & 47.9 & 85.1 & 133 & $14 \%$ & 0.73 & 0.51 & 2.80 \\
\hline Al_1.6_50- & 135 & $350(30 \mathrm{~ms})$ & 933.5 for $20 \mu \mathrm{s}$ & 37.4 & 87.2 & 124.6 & $8 \%$ & 0.67 & 0.48 & 2.40 \\
\hline Al_0.8_100- & 326 & $456(20 \mathrm{~ms})$ & 933.5 for $135 \mu \mathrm{s}$ & 88 & 260 & 348 & $12 \%$ & 1.60 & 1.24 & 4.30 \\
\hline Al_1.6_100- & 320 & $370(32 \mathrm{~ms})$ & 933.5 for $140 \mu \mathrm{s}$ & 115.2 & 225.9 & 341.1 & $6 \%$ & 0.56 & 0.35 & 3.60 \\
\hline
\end{tabular}

\section{Calculation of radiative transfer}

First modelling and calculation of the radiative transfer between a lightning arc column and a plate, for a $100 \mathrm{kA}$ current waveform, was performed in Ref. 26. In the present work, these calculations are completed and extended to a $50 \mathrm{kA}$ arc. In the following, we present the input data, the radiative properties, the radiative transfer solver and the results.

\section{A. Input data}

The intensive thermodynamic properties of the lightning arc were characterized in Ref. 27 using optical emission spectroscopy. In this previous work, we assessed the space- and time-resolved properties within the arc column far from the electrodes under local thermodynamic equilibrium (LTE) assumption. The LTE assumption is certainly not valid in regions very close to the electrodes. However, the thickness of these regions is believed to be so small (see e.g. Ref. 28) that they can be considered as optically thin and their contribution to the total incident radiation on the plate can be neglected. In the bulk plasma column, we have checked several criteria allowing us to assume LTE: (i) The Griem's criterion $^{29}$ for Boltzmann population of electronic levels, (ii) the weak difference between electron temperature, under the acceleration of the electric field, and heavy particle temperature ${ }^{30}$, and, (iii) the time of LTE settlement that is very small compared to the characteristic time of the electrical pulse.

Ionic lines of nitrogen and oxygen are used to determine radial profiles of temperature and electron density of the column over time. The pressure inside the channel is estimated using the determined temperature and electron density distribution combined with the air plasma composition at LTE. Figure 13 shows the obtained temperature and pressure distribution at different instants, for maximum currents of $50 \mathrm{kA}$ and $100 \mathrm{kA}$. For a given instant, the temperature is approximately constant inside the arc channel, and the pressure shows roughly a parabolic shape along the radial direction. In the channel center, the temperature and pressure reach, respectively, $37400 \mathrm{~K}$ and $4.5 \mathrm{MPa}$ at $2 \mu \mathrm{s}$ for $100 \mathrm{kA}$, and decreases 
over time to approximately $19000 \mathrm{~K}$ and $0.8 \mathrm{MPa}$ at $36 \mu$ s. For more details of these diagnostics, the data reduction procedures and the results, the interested readers are referred to Refs. 22 and 27.

(a)

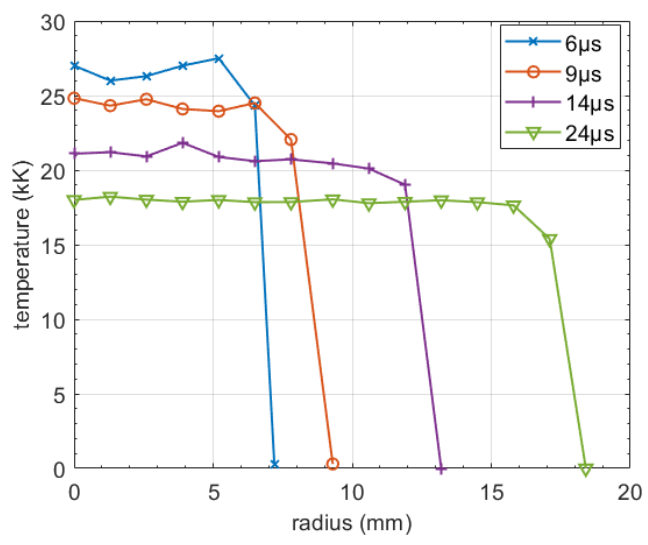

(c)

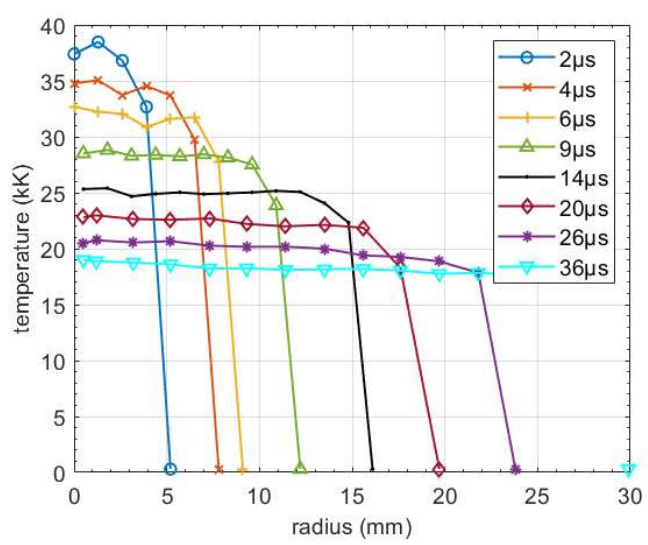

(b)

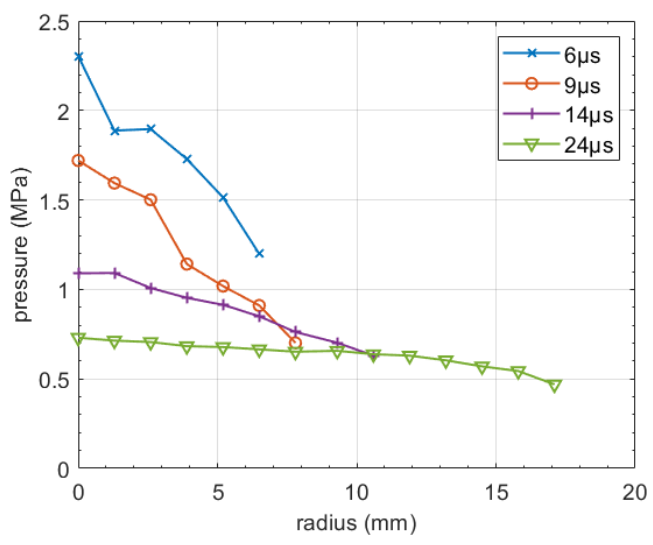

(d)

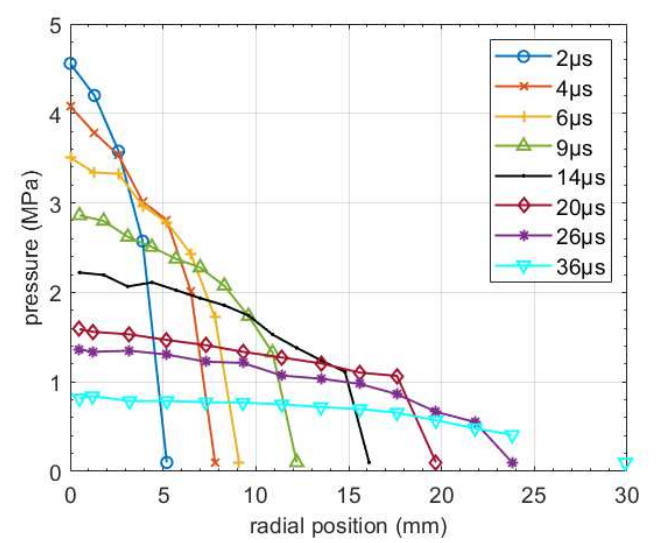

FIG. 13. Temperature and pressure radial distributions for different times and for the arcs with $50 \mathrm{kA}(a-b)$ and $100 \mathrm{kA}$ maximum current $(c-d)$.

\section{B. Radiative properties}

The fundamental spectroscopic data used in this study are gathered in the HTGR EM2C spectroscopic database and were partly described in Refs. 31 and 32. For the sake of clarity, we briefly recall here the radiation mechanisms that are accounted for and outline the extensions made here to cover wider temperature and pressure ranges.

The spectroscopic database of air plasmas radiation was developed first in Refs. 33 and 34. Its accuracy was demonstrated in the temperature range $300-15000 \mathrm{~K}$ and in the wavenumber range 1000 to $150000 \mathrm{~cm}^{-1}$. The database included atomic bound-bound transitions of $\mathrm{N}, \mathrm{O}, \mathrm{N}^{+}, \mathrm{O}^{+}$and molecular bound-bound transitions belonging to 19 electronic systems of $\mathrm{N}_{2}$ (first positive, second positive, Birge-Hopfield 1, Birge-Hopfield 2, Carroll-Yoshino, Worley-Jenkins, Worley), $\mathrm{N}_{2}^{+}$(Meinel, first negative, second negative), $\mathrm{NO}\left(\gamma, \beta, \delta, \varepsilon, \gamma^{\prime}, \beta, 11000 \AA\right.$, infrared), and $\mathrm{O}_{2}$ (Schumann-Runge) systems. Details about the calculation of line intensities and positions for all rovibronic transitions belonging to these molecular systems are provided in Ref. 34. Continuum contributions included N, O, 
$\mathrm{N}_{2}, \mathrm{O}_{2}$ and $\mathrm{NO}$ photoionization, $\mathrm{N}^{-}$and $\mathrm{O}^{-}$photodetachment, $\mathrm{O}_{2}$ (Schumann-Runge) photodissociation and ion-electron, atom-electron and neutral molecule-electron Bremsstrahlung.

The database developed in Refs. 33 and 34 has been extended in Ref. 31 up to $35000 \mathrm{~K}$ by including bound-bound transitions of species $\mathrm{N}^{++}$and $\mathrm{O}^{++}$from the NIST compilation, the photoionization of $\mathrm{N}^{+}$ and $\mathrm{O}^{+}$from the TOPBASE database ${ }^{35,36}$, and the free-free transitions of electron $-\mathrm{N}^{++}$and electron $\mathrm{O}^{++}$pairs. The spectral range has been extended up to $200000 \mathrm{~cm}^{-1}$. Owing to the temperature levels reached in the present application (see Fig. 13), the HTGR database was extended in this study and includes now third ionization stage bound-bound transitions $\left(\mathrm{N}^{+++}\right.$and $\left.\mathrm{O}^{+++}\right)$, as well as photoionization of $\mathrm{N}^{++}$and $\mathrm{O}^{++}$. The spectral range was also extended up to $300000 \mathrm{~cm}^{-1}$.

For the calculation of air plasma composition at chemical equilibrium, the plasma is assumed to be initially constituted of a $\mathrm{N}_{2}-\mathrm{O}_{2}-\mathrm{Ar}$ mixture with $78.46 \%-21.05 \%-0.49 \%$ respective atomic concentrations. The species accounted for in composition calculations are $\mathrm{N}, \mathrm{O}, \mathrm{Ar}, \mathrm{e}^{-}, \mathrm{N}^{+}, \mathrm{N}^{++}, \mathrm{N}^{+++}$, $\mathrm{N}^{++++}, \mathrm{O}^{+}, \mathrm{O}^{++}, \mathrm{O}^{+++}, \mathrm{O}^{++++}, \mathrm{Ar}^{+}, \mathrm{Ar}^{++}, \mathrm{Ar}^{+++}, \mathrm{Ar}^{++++}, \mathrm{N}_{2}, \mathrm{~N}_{2}^{+}, \mathrm{O}_{2}, \mathrm{NO}$, and $\mathrm{NO}^{+}$. The densities of these species at equilibrium are directly calculated from their internal partition functions. Population densities are obtained by solving a set of equations corresponding to the conservation of nuclei $(\mathrm{N}, \mathrm{O}$ and Ar), to Guldberg-Waage dissociation reactions $\left(\mathrm{N}_{2}, \mathrm{O}_{2}, \mathrm{NO}\right)$, Saha ionization reactions, the electrical neutrality, and perfect gas state equations. Note that the gas state equation takes into account Coulombian interactions.

Absorption spectra have been then calculated from the spectroscopic data and plasma composition in the temperature range $300-50000 \mathrm{~K}$ and in the pressure range $0.01-20 \mathrm{MPa}$ with a spectral increment varying linearly from $0.01 \mathrm{~cm}^{-1}$ at $1000 \mathrm{~cm}^{-1}$ to $0.23 \mathrm{~cm}^{-1}$ at $300000 \mathrm{~cm}^{-1}$ (about $4.18 \times 10^{6}$ spectral points), which enables to correctly describe all absorption line shapes. This set of spectral absorption coefficients $\kappa_{v}(T, P)$ for various temperatures $T$ and pressures $P$ at chemical equilibrium constitutes our reference data base for radiative transfer calculations. We have checked that the contribution of minor components like $\mathrm{H}_{2} \mathrm{O}$ and $\mathrm{CO}_{2}$ in air, as well as the possible contribution of carbon originating from the ignition filament, represent less than $5 \%$ of the total radiation and, due to uncertainties on the initial concentrations of hydrogen and carbon particles, we have neglected these contributions.

\section{Radiative transfer solver and calculations}

The incident radiative flux on the plate has been calculated assuming that the temperature and pressure fields inside the plasma column are one-dimensional axisymmetric fields extending along a finite length $H=120 \mathrm{~mm}$ which corresponds to the distance between anode and cathode. Taking into account the column length is necessary as the absorption spectrum of arc channel has non-thick spectral regions and therefore the entire arc column contributes to the incident radiation on the plate. The experimental temperature and pressure radial profiles described above (see Fig. 13) have been extrapolated up to a radius $R=200 \mathrm{~mm}$, assuming that air outside the arc column is at room temperature $300 \mathrm{~K}$ and pressure $0.1 \mathrm{MPa}$, and have been discretized into $n_{r}=200$ uniformly distributed radial points. The radiative incident flux has been calculated from a ray-tracing approach, consisting in generating many rays from each location along a radius of the impacted surface. Such a ray, issued from a radial point $r_{i}$, and characterized by zenithal and azimuthal angles $\theta$ and $\Phi$, is shown in Fig. 14. A uniform discretization of $\theta$ and $\Phi$ ranges, respectively $[0, \pi / 2]$ and $[0, \pi]$, into $n_{\theta}=20$ and $n_{\Phi}=100$ values, was found accurate enough for predicting the radial distribution of the incident flux. For points located close to $r_{i}=R$ and for the earliest experimental times, only few directions intercept the arc volume. This may result in a loss of accuracy on the incident flux but this flux itself tends to 
zero. The Radiative Transfer Equation has been integrated along each ray, enabling to express the spectral intensity incoming at each radial point $r_{i}$ along the direction $(\theta, \Phi)$ and using transmissivities $\tau_{v}(0, s)$, according to:

$$
\begin{gathered}
I_{v}\left(r_{i}, \theta, \Phi\right)=\int_{0}^{s_{\max }}-I_{\nu}^{0}(s) \frac{\partial \tau_{\nu}(0, s)}{\partial s} d s \\
\tau_{v}(0, s)=\exp \left(-\int_{0}^{s} \kappa_{\nu}\left(s^{\prime}\right) d s^{\prime}\right)
\end{gathered}
$$

where $s$ designates the abscissa along the ray and varies from 0 at point $r_{i}$ to $s_{\max }$, corresponding to the intersection of the ray with the boundaries of the computational domain (a cylinder of radius $R$ and height $H) ; \kappa_{v}(s)$ and $I_{v}{ }^{0}(s)$ designate respectively the absorption coefficient and Planck function at abscissa $s$ and wavenumber $v$. Integration in Eq. 9 was carried out with a spatial resolution $s=20 \mu \mathrm{m}$ over which the Planck function is assumed constant. The incoming intensity at $s_{\max }$ has been neglected in this equation. The incoming spectral flux at point $r_{i}$ is then calculated from:

$$
q_{v}^{i n c}\left(r_{i}\right)=2 \int_{\theta=0}^{\frac{\pi}{2}} \int_{\Phi=0}^{\pi} I_{v}\left(r_{i}, \theta, \Phi\right) \cos \theta \sin \theta d \theta d \Phi
$$

This spectral incoming flux has been calculated on the high-resolution wavenumber grid described above and the total radiative flux is thus obtained by integration over the entire wavenumber range.

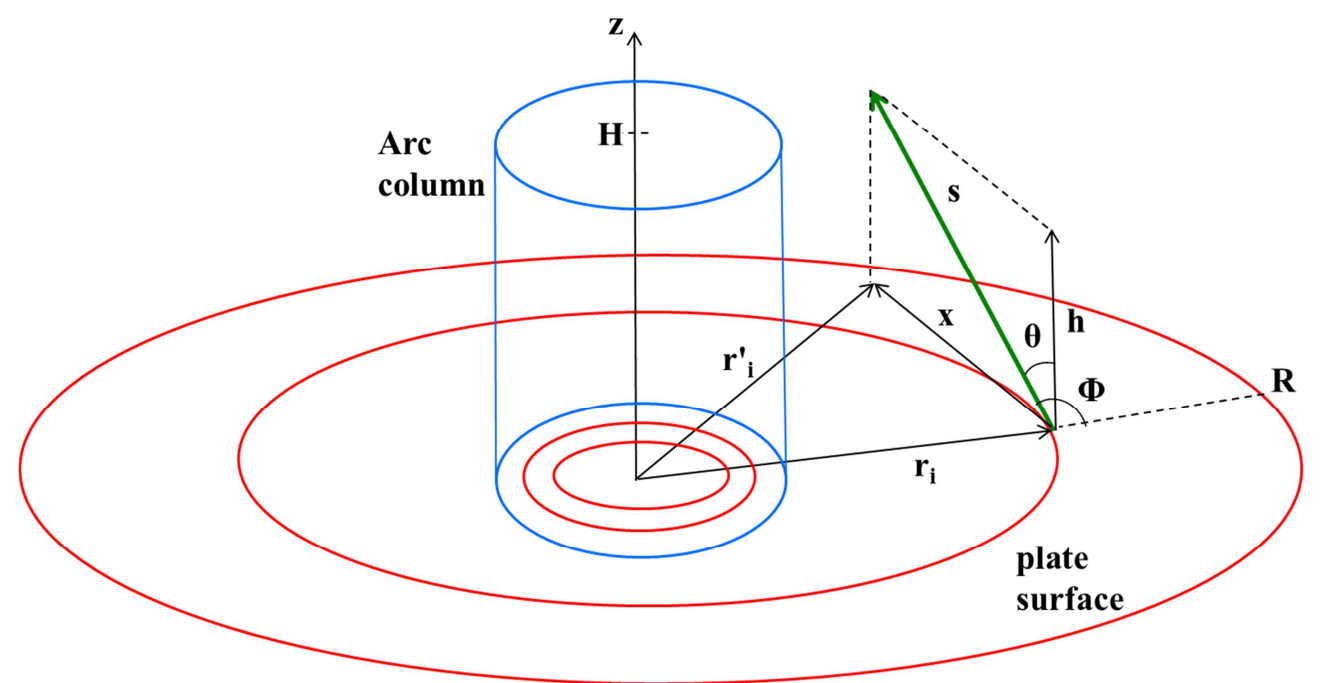

FIG. 14. Ray tracing approach.

Figures $15(a)$ and 15(c) show the radial distribution of the calculated total incoming radiative flux for $50 \mathrm{kA}$ and $100 \mathrm{kA}$, respectively, at the different instants where temperature and pressure fields were measured. The figure focuses on the first $30 \mathrm{~mm}$ near the center of the arc, although the distribution has been obtained up to the radius $R=200 \mathrm{~mm}$. The incident radiative flux distributions are strongly correlated with the temperature profiles shown in Fig. 13, and also exhibit the arc cooling and the increasing of the arc radius versus time. 
In Figs. 15(b) and 15(d), we present the spectral distributions of this incoming radiative flux at time $14 \mu \mathrm{s}$ for $50 \mathrm{kA}$ and $100 \mathrm{kA}$, respectively. Two radial locations are presented, at the arc axis $(r=0)$ and at a position close, but outside the arc root radius $(r=14.5 \mathrm{~mm}$ for $50 \mathrm{kA}$ and $r=16.5 \mathrm{~mm}$ for $100 \mathrm{kA}$ ). The spectrum at the center of the arc column impact on the plate exhibits a characteristic behavior of thermal plasma at temperature and pressure about $21000 \mathrm{~K}$ and $1.1 \mathrm{MPa}$ for $50 \mathrm{kA}$, and $25000 \mathrm{~K}$ and $2.5 \mathrm{MPa}$ for $100 \mathrm{kA}$, with strong contribution of monatomic ion lines, and strong continuum contribution due to line overlapping (Stark broadening) and photo-ionization. For the radial point just outside the arc channel (see Fig. 4), the spectral incident flux exhibits a strong absorption by cold air, in particular the strong absorption due to $\mathrm{O}_{2}$ Schumann-Runge continuum between 60000 and $75000 \mathrm{~cm}^{-1}$ and to the $\mathrm{N}_{2}$ VUV systems above $100000 \mathrm{~cm}^{-1}{ }^{34}$

(a)

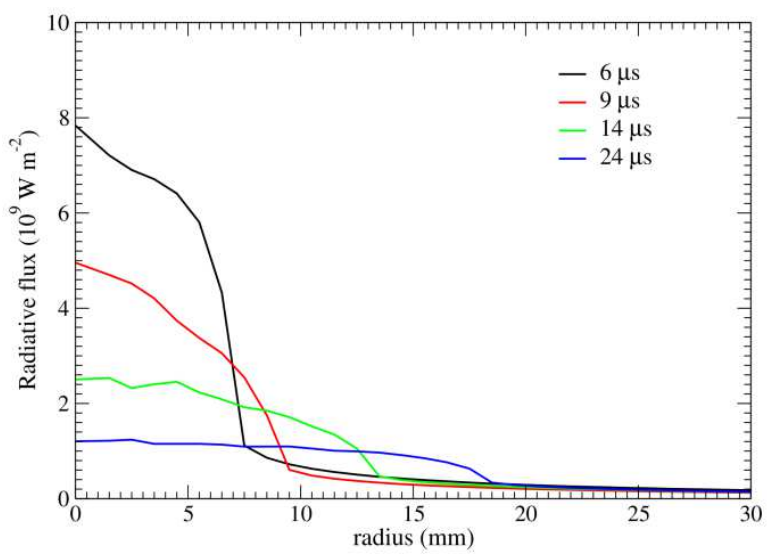

(c)

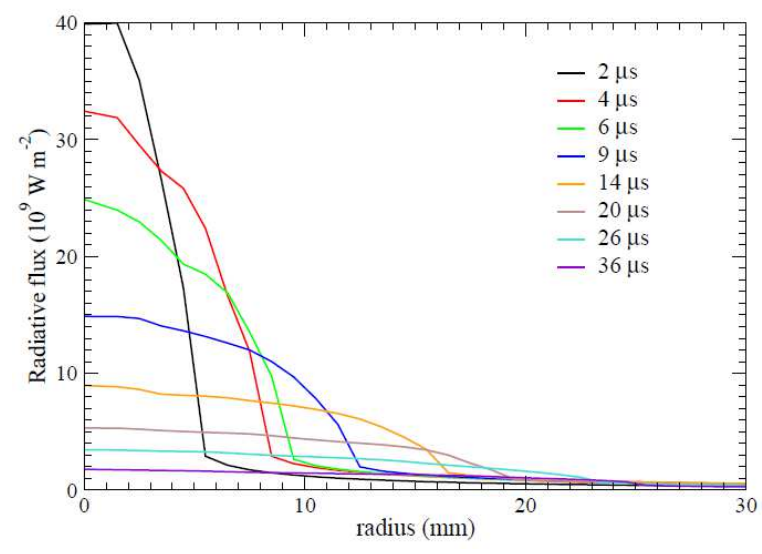

(b)

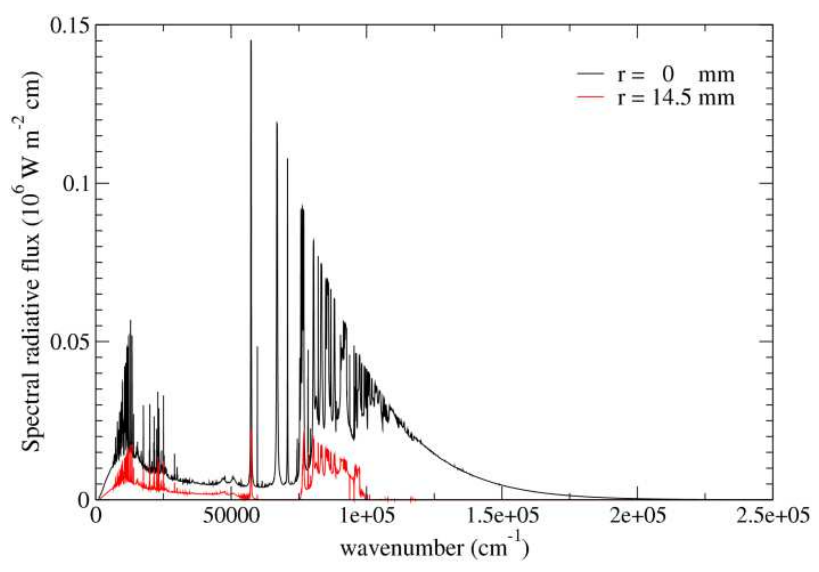

(d)

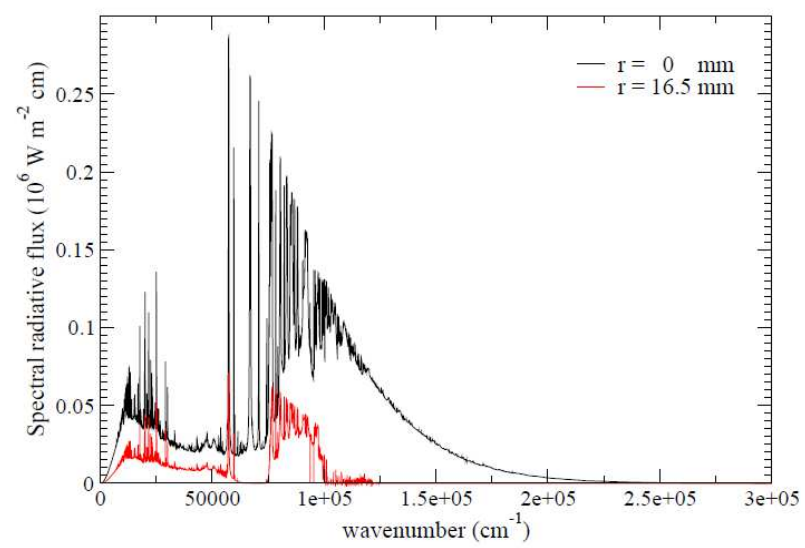

FIG. 15. Radial distribution of the total radiative incident flux and spectral distribution of these fluxes at two radii at $14 \mu \mathrm{s}$. $(a-b) 50 \mathrm{kA}(c-d) 100 \mathrm{kA}$.

Figure 16 shows finally the temporal evolution of the total radiative flux incident on the whole plate, i.e. integrated on the disc of radius $R=200 \mathrm{~mm}$, for the two current amplitudes. 
(a)

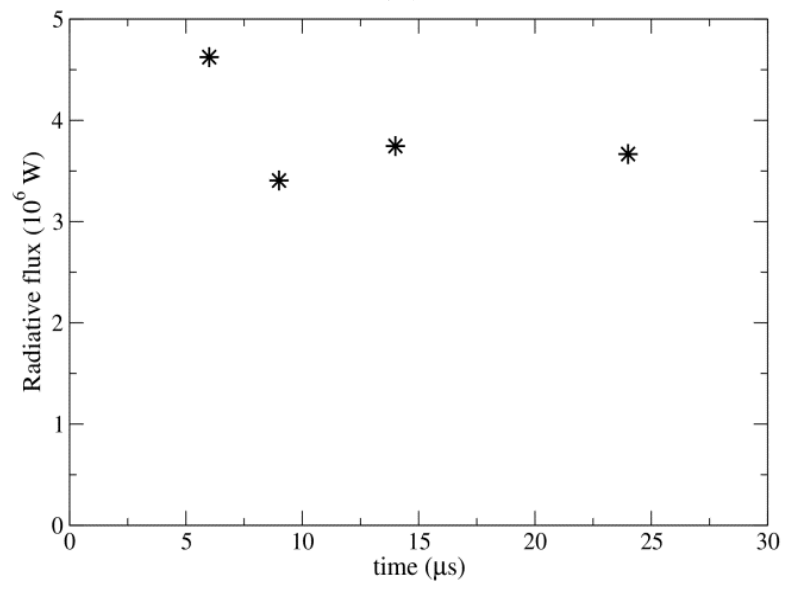

(b)

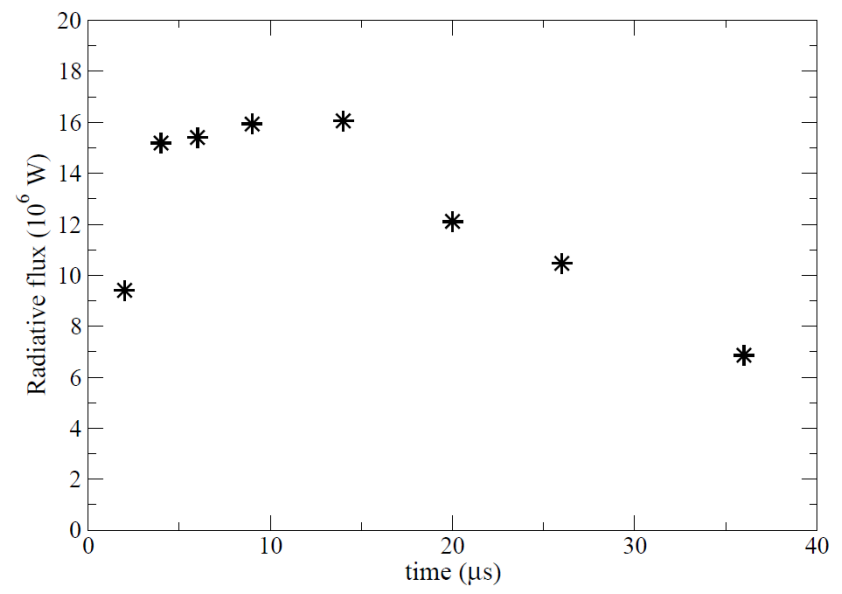

FIG 16. Temporal evolution of the total radiative incident flux for $50 \mathrm{kA}(a)$ and $100 \mathrm{kA}(b)$.

\section{Discussion}

Based on the heat and energy fluxes estimated by the inverse method and the calculated radiative flux obtained in the previous section, we can analyze and discuss the energy budget during the arc-plate interaction, and the role of the three main mechanisms: the radiative and ion-electron heat fluxes, and Joule heating.

The arc channel itself has an important consumption of energy. From an electrical analysis, we can obtain the electrical power dissipated inside the arc column by Joule heating. The electric power and the energy dissipated in the arc column are estimated using the current and voltage measurements. ${ }^{21}$ For the cylindrical arc column of $120 \mathrm{~mm}$ length and current waveform of $100 \mathrm{kA}$ peak, the dissipated energy within the column cumulated in the first $50 \mu \mathrm{s}$ is around $3100 \mathrm{~J}$.

The volumetric power $P_{\text {Joule }}$ released by Joule heating inside the plate is calculated in each volume element by solving the Poisson equation (Sec. III.A). Integrating this power over the volume and time we obtain, for the aluminum plate and $100 \mathrm{kA}$ case, an energy of $4.1 \mathrm{~J}$. Also, this total energy release can be analytically deduced by the expression $P_{\text {Joule }}=j^{2} / \sigma_{e}$, and assuming a radial distribution outside the arc root radius for the current density $j$ inside the material. With this simplification, we obtain a total energy for the entire current waveform around $1.2 \mathrm{~J}$ for $50 \mathrm{kA}$ and $4 \mathrm{~J}$ for $100 \mathrm{kA}$ case. The electrical conductivities of the studied materials are very high (higher than $10^{6} \mathrm{~S} \mathrm{~m}^{-1}$ ), which explain this small dissipated energy by Joule heating. It can be neglected when compared to the other mechanisms.

The heating of the plate by the ion-electron heat flux is generally considered as the main heat transfer mechanism. ${ }^{5-20,37}$ This heat flux is frequently approximated by the product between the arc current density and EVF. Assuming that the EVF is constant during the arc lifetime, we can obtain the energy associated to the ion-electron heat flux by integration of the current density over the plate surface and over time. This leads to a simple relation $E V F \times Q$, where $Q$ is the transferred charge from the arc to the plate, and is equal to $2.9 \mathrm{C}$ for $50 \mathrm{kA}$ and $5.4 \mathrm{C}$ for $100 \mathrm{kA}$ current waveform. The voltage fall term $E V F$ is a parameter with significant uncertainty and is assumed to be a function of the electrode material, the plasma composition, etc. ${ }^{7-10}$ However, many studies indicate and commonly assume that EVF can take values in the range of 10 to $25 \mathrm{~V}$. ${ }^{6,12,13,20,37}$ Therefore, we can propose a rough 
estimation for the bounds of the energy transferred by ion-electron heat flux from 29 to $72 \mathrm{~J}$ for $50 \mathrm{kA}$ and from 54 to $135 \mathrm{~J}$ for $100 \mathrm{kA}$.

From the total radiative incident flux presented in the previous section, we can estimate the radiative incident energy from the arc to the plate. Integrating with respect to time the results of Fig. 16 and assuming a linear decrease of the total radiative flux from the last measurement time to $100 \mu \mathrm{s}$, we obtain, for $50 \mathrm{kA}$ and $100 \mathrm{kA}$ waveforms, an incident radiative energy of around $250 \mathrm{~J}$ and $600 \mathrm{~J}$, respectively. To obtain the energy that is effectively transferred to the material, one has to consider the absorption coefficient of the plate, which is a parameter highly dependent on the surface state and is probably affected during the arc interaction. Nevertheless, for aluminum materials the absorption coefficient is expected to vary from 0.3 to 0.8 , which allows us to estimate bounds of the total radiative energy. Hence, the absorbed radiative energy can be estimated to vary from 75 to $200 \mathrm{~J}$ for $50 \mathrm{kA}$, and from 180 to $480 \mathrm{~J}$ for $100 \mathrm{kA}$.

Figure 17 shows a diagram illustrating the different heat fluxes at arc-material interface, the volumetric power dissipated by Joule heating and the losses at incident and rear surface.

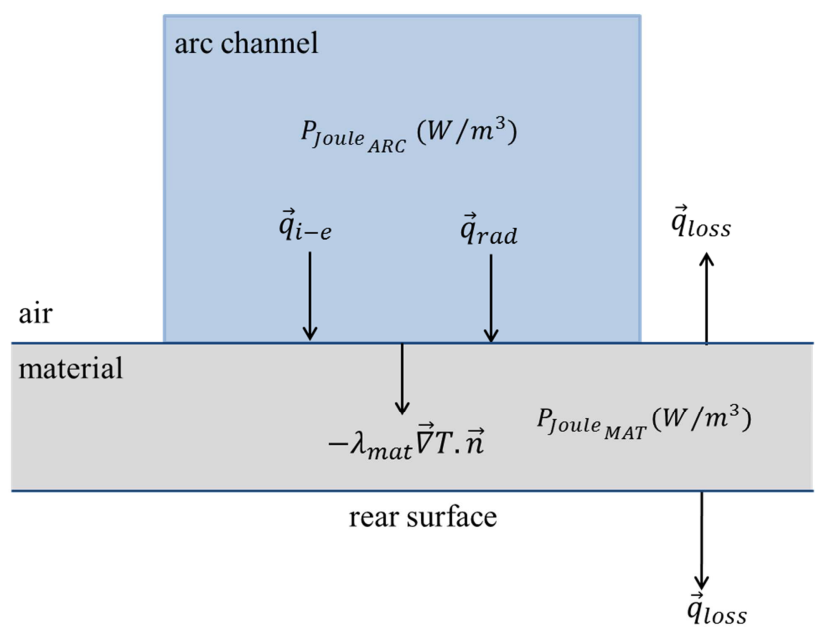

FIG 17. Diagram of the energy balance at the arc-material interface.

The results of the measured transferred energy and the estimated energy presented in Table III show values in accordance with the theoretical estimations. The transferred energies for $50 \mathrm{kA}$ waveforms are around $150 \mathrm{~J}$ for the different materials and polarities. For the $100 \mathrm{kA}$ waveform, they reach approximately $330 \mathrm{~J}$ for tungsten plates in both polarities and similar values for aluminum at negative polarity. For aluminum in positive polarity the energy is around $300 \mathrm{~J}$.

Analyzing the heat fluxes $q_{1}$ and $q_{2}$ obtained by the inverse method, we could propose a correspondence with radiative and ion-electron heat fluxes. We observe that, in general, $q_{l}$ could be associated with $q_{i-e}$ while $q_{2}$ is more likely to represent $q_{\text {rad }}$. Theoretical estimations show that radiative flux is more sensitive to the current amplitude than ion-electron heat flux, and from the results presented in Table III, we observe that $E_{2}$ increases more with the current than $E_{1}$. Also, by examining the values of the $\alpha$ coefficients and the spatial distribution of each profile, we observe a good correlation between $q_{2}$ and $q_{\text {rad }}$. Different materials should not have a strong impact on $q_{\text {rad }}$, however this should have an influence on $q_{i-e}$, since the EVF is a function of the surface temperature and the work function. ${ }^{7,17-20}$ This material dependency is not clearly observed, as there is not significant modification on calculated values for different materials. Therefore, this correspondence cannot be 
considered as fully corroborated by the obtained results. Nevertheless, let us recall that the total transferred energy is well predicted by the estimated sum $E_{1}+E_{2}$ when compared to the measured value $\Delta E$.

All the energies discussed above are summarized in Table IV. The highest energy listed is the Joule heating released in the arc column. This energy is dissipated mainly in the air plasma heating, the column expansion, the induced shock wave and the radiative losses. As discussed above, Joule heating in the plate is negligible compared to other energy sources. Contrary to the assumption that is usually accepted regarding the plasma-material exchange, the radiative flux appears to be at least of the same order of magnitude as the ion-electron heat flux and could be much higher than this last one. This result shows that the radiative flux is a very important mechanism in the energy balance at the plasma-material interface and can be the main process in the thermal constraint imposed to the plate for high current arcs.

TABLE IV. Estimated energy balance for different arc/plate interaction mechanisms.

\begin{tabular}{|c|c|c|c|}
\hline \multirow{2}{*}{ Source Mechanisms } & \multirow{2}{*}{$\begin{array}{l}\text { Approximate } \\
\text { expression }\end{array}$} & \multicolumn{2}{|c|}{ Approximate Values (J) } \\
\hline & & $50 \mathrm{kA}$ & $100 \mathrm{kA}$ \\
\hline Joule heating - arc column & $\int_{t} V_{a r c} I_{a r c} d t$ & 1800 & 3100 \\
\hline $\begin{array}{l}\text { Joule heating - aluminum } \\
\text { plate }\end{array}$ & $\int_{t} \int_{V} \frac{j^{2}}{\sigma} d V d t$ & 1.2 & 4 \\
\hline $\begin{array}{l}\text { Energy from ion-electron heat } \\
\text { flux }\end{array}$ & $E V F \times Q$ & $29-72$ & $54-135$ \\
\hline Energy from radiative flux & $\iint_{t} q_{S} q_{r a d} d S d t$ & $75-200$ & $180-480$ \\
\hline $\begin{array}{l}\text { Estimated transferred energy } \\
\text { from IRT }\end{array}$ & $\Delta E$ & $133-195$ & $300-360$ \\
\hline $\begin{array}{l}\text { Transferred energy from } \\
\text { inverse method }\end{array}$ & $E_{1}+E_{2}$ & $112-154$ & $251-348$ \\
\hline
\end{tabular}

\section{Conclusion}

In this work we have studied the energy exchange during the interaction between a pulsed lightning arc and a metallic plate. An experimental parametric study on plate material, thickness, current peak level and arc polarity, is carried out using IRT to assess the rear surface temperature distribution over time. Eighteen configurations are tested and analyzed. Examinations after test on the damage caused at the attachment point are done. These analyses showed that the damage spot are mostly circular, with a small inhomogeneity streak for aluminum and titanium cases at $100 \mathrm{kA}$, which are probably related to the ignition phase.

An inverse method is used to estimate the incident flux based on the rear surface temperature measurements. The direct problem was numerically solved taking into account heat conduction and Joule heating. It showed that two different fluxes are needed to accurately adjust the measured data. 
Good agreement was observed between the measured and calculated temperature profiles, and also between the measured energy transferred to the plate and the energy provided by the estimated flux. A transferred energy of around $150 \mathrm{~J}$ is observed for the $50 \mathrm{kA}$ current waveforms, and is higher than $300 \mathrm{~J}$ for the $100 \mathrm{kA}$ arcs.

A model for the radiative exchange between the arc channel and the plate surface is developed using a ray tracing method and a line by line approach in a large spectral range. Computations are performed using experimental distributions of temperature and pressure inside the channel and a reliable and exhaustive spectroscopic database.

The main mechanisms, responsible for the arc-plate energy exchange, are estimated and discussed. For the studied metallic plates, the Joule heating is negligible compared to the incident fluxes. The radiative flux, which is normally neglected for low and moderate current applications, appears to be higher than the ion-electron heat flux for these pulsed high current arcs.

\section{Acknowledgment}

The authors wish to thank the French Civil Aviation Authority (DGAC) for its support. Radiation computations were performed using HPC resources from GENCI-IDRIS (Grant A0062B00209).

\section{Data availability}

The data that support the findings of this study are available within the article.

\section{References}

${ }^{1}$ B. Fisher, R. Taeuber, and K. Crouch, in AIAA 26th Aerospace Sciences Meeting, Reno, USA (1988).

${ }^{2}$ C. Jones, D. Rowse, and G. Odam, in Int. Conf. on Lightning and Static Electricity, Seattle, USA (2001).

${ }^{3}$ SAE ARP5577 and Eurocae ED-113, Aircraft Lightning Direct Effects Certification (AE-2 Lightning Committee, SAE International, London, 2008).

${ }^{4}$ SAE ARP5412B and Eurocae ED-105A, Aircraft Lightning Environment and Related Test

Waveforms (AE-2 Lightning Committee, SAE International, London 2013).

${ }^{5}$ L. Chemartin, P. Lalande, B. Peyrou, A. Chazottes, P. Q. Elias, C. Delalondre, B. G. Cheron , and F. Lago, J. AerospaceLab 5, AL05-09 (2012).

${ }^{6}$ L. Chemartin, P. Lalande, C. Delalondre, B. Cheron and F. Lago, J. Phys. D: Appl. Phys. 44, 194003 (2011).

${ }^{7}$ M. S. Benilov, and A. Marotta, J. Phys. D: Appl. Phys. 28, 1869 (1995).

${ }^{8}$ M. S. Benilov, and M. D. Cunha, J. Phys. D: Appl. Phys. 35, 1736 (2002).

${ }^{9}$ M. S. Benilov, M. D. Cunha, and G. V. Naidis, Plasma Sources Sci. Technol. 14, 517 (2005).

${ }^{10}$ M. S. Benilov, J. Phys. D: Appl. Phys. 41, 144001 (2008).

${ }^{11}$ K. C. Hsu, K. Etemadi, and E. Pfender, J. Appl. Phys. 54, 1293 (1983).

${ }^{12}$ C. Delalondre, and O. Simonin, J. Physique Coll. 51, 199 (1990). 
${ }^{13}$ J. J. Lowke, R. Morrow, and J. Haidar, J. Phys. D: Appl. Phys. 30, 2033 (1997).

${ }^{14}$ F. Lago, J. J. Gonzalez, P. Freton, and A. Gleizes, J. Phys. D: Appl. Phys. 37, 883 (2004).

${ }^{15}$ N. A. Sanders, and E. Pfender, J. Appl. Phys. 55, 714 (1984).

${ }^{16}$ P. G. Jönsson, R. C. Westhoff, and J. Szekely, J. Appl. Phys. 74, 5997 (1993).

${ }^{17}$ J. Haidar, J. Appl. Phys, 84, 351 (1998).

${ }^{18}$ G. Xu, J. Hu, and H. L. Tsai, J. Appl. Phys. 104, 103301 (2008).

${ }^{19}$ Z. H. Rao, S. M. Liao, and H. L. Tsai, J. Appl. Phys. 107, 044902 (2010).

${ }^{20}$ M. Rong, Q. Ma, Y. Wu, T. Xu, and A. B. Murphy, J. Appl. Phys. 106, 023308 (2009).

${ }^{21}$ R. Sousa Martins, L. Chemartin, C. Zaepffel, P. Lalande, and A. Soufiani, J. Phys. D: Appl. Phys. 49, 185204 (2016).

${ }^{22} \mathrm{R}$. Sousa Martins, Experimental and theoretical studies of lightning arcs and their interaction with aeronautical materials (PhD thesis, Ecole Centrale Paris, 2016).

${ }^{23}$ M. R. Sonne, C. C. Tutum, J. H. Hattel, A. Simar, and B. de Meester, J. Mater. Process. Technol. 213, 477 (2013).

${ }^{24}$ R. W. Powell, and R. P. Tye, J. Less. Common Met. 3, 226 (1961).

${ }^{25}$ G. K. White, and M. L. Minges . Int. J. Thermophys. 18, 1269 (1997).

${ }^{26}$ R. Sousa Martins, Ph. Riviere, L. Chemartin, C. Zaepffel, and A. Soufiani, in Proc. $16^{\text {th }}$ Int. Heat Transfer Conf., Beijing, China (2018).

${ }^{27}$ R. Sousa Martins, C. Zaepffel, L. Chemartin, P. Lalande, and A. Soufiani, J. Phys. D: Appl. Phys. 49, 415205 (2016).

${ }^{28}$ M. Baeva, M.S. Benilov, N.A. Almeida and D. Uhrlandt, J. Phys. D: Appl. Phys. 49, 245205 (2016)

${ }^{29}$ H.R. Griem, Principles of plasma spectroscopy, (Cambridge Monographs on Plasma Physics, 1997, p. 214)

${ }^{30}$ Y.P. Raizer, Gas discharge physics (Springer-Verlag, 1991, pages 285, 13-14).

${ }^{31}$ B. Peyrou, L. Chemartin, P. Lalande, B. Cheron, Ph. Riviere, M. Y. Perrin, and A. Soufiani, J. Phys. D: Appl. Phys. 45, 455203 (2012).

${ }^{32}$ A. Soufiani, Ph. Riviere, and M. Y. Perrin, High temperature gas radiation (HTGR) database and models (Von Karman Institute Lecture Series, STO-EN-AVT-218, 2013)

${ }^{33}$ S. Chauveau, C. Deron, M. Y. Perrin, Ph. Riviere, and A. Soufiani, J. Quant. Spectrosc. Radiat. Transfer 77, 113 (2003).

${ }^{34}$ S. Chauveau, M. Y. Perrin, Ph. Riviere, and A. Soufiani, J. Quant. Spectrosc. Radiat. Transfer 72, 503 (2002). 
${ }^{35}$ W. Cunto, C. Mendoza, F. Ochsenbein and C.J. Zeippen, A\&A 275, L5 (1993)

${ }^{36}$ The Opacity Project Team, The Opacity Project Vol. 1 (Institute of Physics Publications, Bristol, UK, 1995).

${ }^{37}$ F. Valensi, P. Ratovoson, M. Razafinimanana, M. Masquere, P. Freton and A. Gleizes, J. Phys. D: Appl. Phys. 49, 255202 (2016). 